\title{
A Review of the Use of UHPFRC in Bridge Rehabilitation and New Construction in Switzerland
}

\author{
Numa Bertola*, Philippe Schiltz ${ }^{\dagger}$, Emmanuel Denarié and Eugen Brühwiler
}

Laboratory for Maintenance and Safety of Structures (MCS), School of Architecture, Civil and Environmental Engineering (ENAC), Swiss Federal Institute of Technology (EPFL), Lausanne, Switzerland

Ultra-High-Performance Fibre Reinforced Cementitious Composite (UHPFRC) provides solutions to enhance existing structures and design innovative new structures. Structural UHPFRC offers 3-5 times higher compressive and tensile strengths than ordinary concrete. Due to its strain-hardening behavior and dense matrix, structures made of UHPFRC remain crack-free and waterproof, guaranteeing durability. UHPFRC has been used particularly in Switzerland with more than 280 applications since 2003. A review of UHPFRC applications in the country is proposed in this paper. Ten bridge case studies are presented, including five strengthening of existing structures and five new designs. These structures were chosen to assess the multiple benefits that UHPFRC provides compared

Elias G. Dimitrakopoulos, Hong Kong University of Science and Technology, Hong Kong, SAR China

Reviewed by: Jing $Y u$,

Sun Yat-sen University, China Sandra Nunes, University of Porto, Portugal

*Correspondence: Numa Bertola numa.bertola@epfl.ch

${ }^{\text {t}}$ Present address:

Philippe Schiltz,

Bridgology SA, Epalinges, Switzerland

Specialty section:

This article was submitted to

Bridge Engineering,

a section of the journal Frontiers in Built Environment

Received: 02 September 2021 Accepted: 01 November 2021 Published: 16 November 2021

Citation:

Bertola N, Schiltz P, Denarié E and Brühwiler E (2021) A Review of the Use

of UHPFRC in Bridge Rehabilitation and New Construction in Switzerland.

Front. Built Environ. 7:769686. doi: 10.3389/fbuil.2021.769686 to traditional reinforced-concrete structures. Besides structural efficiency, several construction criteria are considered, such as construction costs, material durability, environmental impacts, and construction time. Structural rehabilitation made with UHPFRC leads to cost-effective interventions, and this material also helps to preserve heritage structures. Due to its specific mechanical properties, UHPFRC enables new structures with distinctive aesthetic designs with reduced construction time. The crucial contribution of research to the first case studies is also highlighted. This link between Swiss universities and the construction industry has quickly transitioned UHPFRC Technology from academic studies to real-world applications. Nowadays, the UHPFRC Technology is maturing and applications are common in the country.

Keywords: UHPFRC, bridge strengthening, lightweight bridge structures, structural design, infrastructure management

\section{INTRODUCTION}

Reinforced concrete (RC) structures, such as bridges or buildings, have been widely built worldwide since the middle of the 20th century. However, they often show durability issues, like rebar corrosion or alkali-aggregate reaction. These degradation mechanisms can significantly reduce their structural performance. The rehabilitation of deteriorated structures typically has significant intervention and user costs (Frangopol and Liu, 2007). Traditional retrofitting solutions using concrete and repair mortar are not durable enough, meaning that effective, sustainable, and economic rehabilitation strategies of RC structures are needed (Bocchini et al., 2014).

Ultra-High Performance Fibre Reinforced Cementitious Composite (UHPFRC) is made of a mix of cement (and other reactive powders), additives, fine aggregate particles (with a maximum grain size of $1 \mathrm{~mm}$ ), water, admixtures, and a large amount of slender discontinous steel fibers (Brühwiler, 


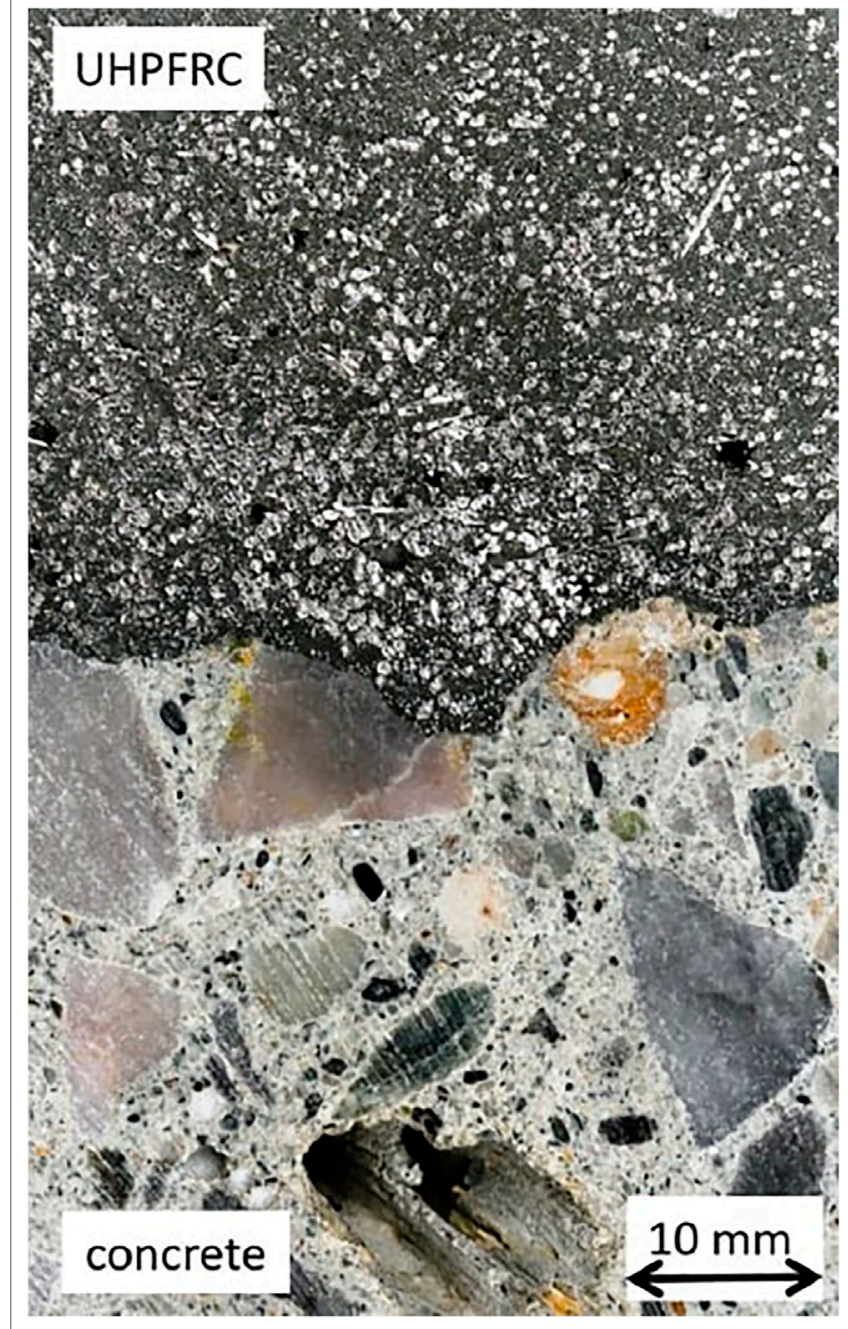

FIGURE 1 | UHPFRC - concrete core showing the apparent difference between the two materials. Adapted from (Brühwiler, 2018).

2016b; Yoo and Yoon, 2016). UHPFRC materials should be differentiated from concrete as it does not comply with the "concrete" definition as shown in Figure 1. UHPFRC should thus be treated as a unique material with specific properties, and this also implies specific design codes and execution processes. Academic work has played a significant role in developing the concept of UHPFRC as an enhancement of structural resistance and durability of existing structures (Brühwiler, 2016b). This concept has been referred to as "UHPFRC Technology" (Brühwiler, 2020).

UHPFRC Technology has been widely used to enhance existing bridges (Martin-Sanz et al., 2016; Azmee and Shafiq, 2018). First applications on RC structures have been realized since 2009 in several countries such as Slovenia. (2009) (Denarié and Sajna, 2009), Japan (2014). (Kosaka et al., 2015), Austria (2015) (Hadl et al., 2015), the USA (2016) (Haber et al., 2017), and Germany (2017) (Pelke et al., 2018), all based on the Swiss UHPFRC concept of enhancement of existing bridges. UHPFRC has also been used to strengthen orthotropic steel decks in numerous countries such as in the Netherlands (2006) (Buitelaar et al., 2006) and in China since 2016 (Cao et al., 2016), where this concept has been used at least thirty times across twelve provinces (Shao et al., 2019).

New bridge designs have also involved UHPFRC as the primary construction material in numerous cases worldwide. The first road bridge application (2002) is in France and UHPFRC has proven its durability properties 10 years after construction (Toutlemonde et al., 2013). Numerous applications have then followed worldwide. For instance, more than 120 bridges in UHPFRC have been built in Malaysia since 2010 (Graybeal et al., 2020) and several applications in Colombia since 2016 (Núñez et al., 2019). Several footbridges made of UHPFRC have been built, such as in Japan since 2002 (Tanaka et al., 2002) in France since 2011 (Mazzacane et al., 2011), in the Czech Republic since 2014 (Coufal et al., 2016) and in Spain since 2017 (López et al., 2016).

Rational design rules have been established for the application and implementation of UHPFRC in structural engineering. In Switzerland, the Technical Leaflet SIA 2052 (Swiss Society of Engineers and Architects, 2016) has been introduced in 2016. This technical leaflet includes both new designs made of UHPFRC and concepts to enhance RC structures with a layer of reinforced UHPFRC (R-UHPFRC). This document is based on research findings over 20 years that have been validated using both laboratory tests and full-scale applications.

In Switzerland, several pioneer applications have been realized since 2003. This paper presents a review of the $280+$ applications of UHPFRC in the country. Five enhancements of existing bridges and five new structures are chosen as case studies. In this review, the use of UHPFRC Technology in these case studies is assessed based on the structural efficiency, aesthetics, construction time, project costs, and environmental impacts. The objective of this paper is to summarize the state of the art of UHPFRC Technology in Switzerland. Future challenges and opportunities are then highlighted.

This manuscript is organized as follows. Section 2 shows the structural properties of UHPFRC and RC structures strengthened with an R-UHPFRC layer. In Section 3, the ten case studies are presented (five strengthenings of existing structures and five new designs). Interventions and new designs are compared to traditional solutions in Section 4. Discussion and conclusion sections then follow.

\section{MECHANICAL BEHAVIOR OF UHPFRC}

\section{Structural Performance}

UHPFRC mixes have been developed over 30 years of research and applications worldwide. The mechanical properties and structural performance of UHPFRC are summarized in (Brühwiler, 2020). UHPFRC has significant resistance in tension (up to $16 \mathrm{MPa}$ ) and compression (up to $180 \mathrm{MPa}$ ). Due to its strain-hardening behavior, UHPFRC is a crack-free material and waterproof under service conditions, providing robust protection again environmental actions such as water and chloride ion ingress. Young's modulus in both tension and compression is between 45 and $50 \mathrm{GPa}$. This value is relatively close to existing RC structures that often present 

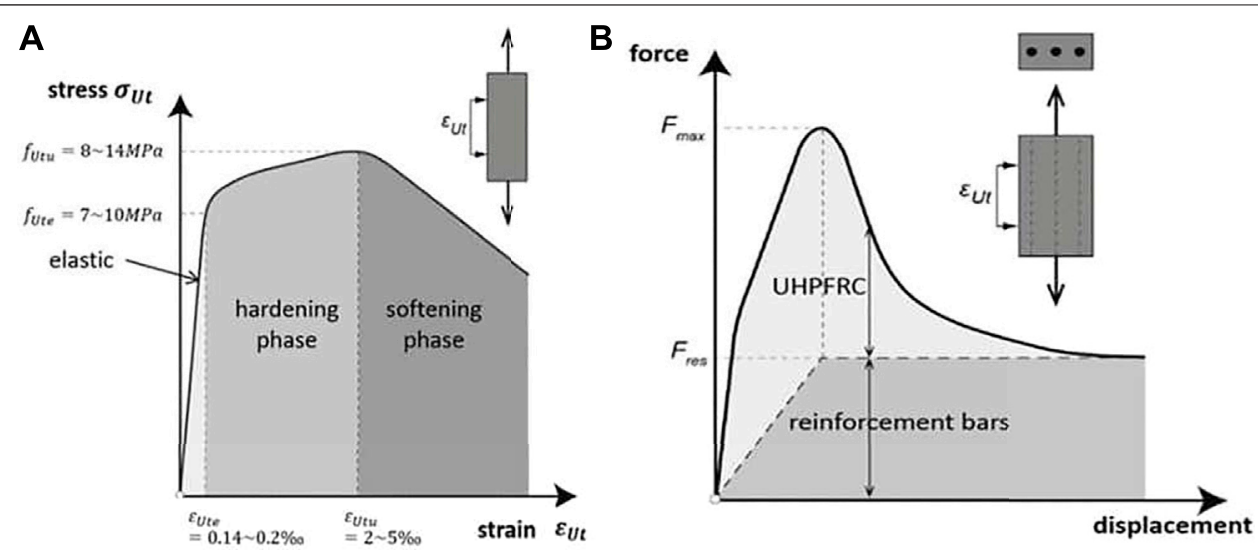

FIGURE 2 | Characteristic tensile behavior of (A) plain UHPFRC and (B) Reinforced-UHPFRC. Adapted from (Brühwiler, 2020).

elastic modulus between 30 and $45 \mathrm{GPa}$, limiting induced stresses due to temperature and shrinkage effects.

The tensile behavior of UHPFRC and R-UHPFRC is presented in Figure 2. In the tensile strain hardening phase, the elastic modulus is typically reduced by $60-70 \%$. The significant strain hardening deformation $\varepsilon_{U t u}$ is larger than $2 \%$, associated with tensile strength $f_{U t u}$ between 8 and $14 \mathrm{MPa}$ (Figure 2A). To exhibit this mechanical behavior, the material requires a fibre content larger than 3 volume-\% of straight high-strength steel fibers.

The UHPFRC tensile response depends on the fibre orientation during casting, which is also influenced by the element thickness. Nevertheless, the anisotropic fibre orientation is mitigated by the high fibre content and mixing procedure. Typically, a fibre orientation coefficient is applied on mechanical properties between 0.8 and 1 depending on the element thickness (Swiss Society of Engineers and Architects, 2016).

The tensile strength can be significantly improved using complementary steel reinforcement bars (Oesterlee et al., 2008a), called reinforced UHPFRC (R-UHPFRC). The rebars also help reduce the scatter of material properties. Typically, small rebar diameters with low spacing are chosen to provide in-plane continuity to the UHPFRC layer. Figure 2B shows that rebars also improve the deformation capacity and strain-hardening behavior of UHPFRC. The mechanical behavior of R-UHPFRC is described by the superposition of the reinforced steel and the UHPFRC tensile behaviors. Under compression, the mechanical behavior of UHPFRC is characterized by a linear stress-strain relation up to $80 \%$ of the compressive strength $\left(0.8 f_{U_{c}}\right)$ that is usually in the range of $150-200 \mathrm{MPa}$. Beyond, a slight non-linear phase is observed until $f_{U c}$. Heat treated UHPFRC exhibits higher strength and a ductile post-peak behavior (Graybeal, 2007).

\section{UHPFRC-RC Composite Elements}

UHPFRC is often used as a reinforcement layer added to RC structures. This layer can enhance both the structural performance and durability of existing structures (Denarié and
Brühwiler, 2006). Typical concepts of intervention on reinforced concrete structures are shown in Figure 3. The selected concept depends on the objective of the intervention (strengthening and/ or rehabilitation). When the intervention aims only to protect the existing structure, a UHPFRC layer between 20 and $40 \mathrm{~mm}$ is sufficient (Figure 3A). When the objective of the intervention is to enhance the structural performance, a UHPFRC layer of at least $40 \mathrm{~mm}$ is required to ensure at least $15 \mathrm{~mm}$ of cover for the reinforcement steel bars (Figure 3B). In such situations, the protective objective is fulfilled as well. When corroded rebars are observed in the existing structure, concrete is removed to the required depth to replace these rebars (Figure 3C). The depth of the UHPFRC layer thus depends on the condition of the RC structure. In all cases, these interventions lead to structural systems with monolithic behavior between R-UHPFRC and RC elements (Oesterlee et al., 2008b).

\section{UHPFRC APPLICATIONS IN SWITZERLAND}

\section{Introduction}

Research on UHPFRC at the laboratory of maintenance and safety of structures (MCS) at EPFL has started in early 2000 such as (Habel et al., 2002; Charron et al., 2007) among others. Due to the excellent connection between academia and the construction industry in Switzerland, it was possible to rapidly transfer the UHPFRC Technology into practice. In this section, ten selected applications of UHPFRC in the country are presented (Figure 4). In most of these applications, MCS has been directly (as design engineer) or indirectly (consultant) involved in these projects, leading to a rapid knowledge transfer from academic research to construction companies and design offices.

The first bridge application is the rehabilitation of Morge Bridge in 2004, a RC road bridge built in 1954. Since then, also several historical bridges have been rehabilitated, including the Dalvazza Bridge (built in 1925) and the Guillermaux Bridge (1920) of high cultural value, allowing the preservation of these bridges without modifying their original aspect while increasing the load bearing capacity for modern use 

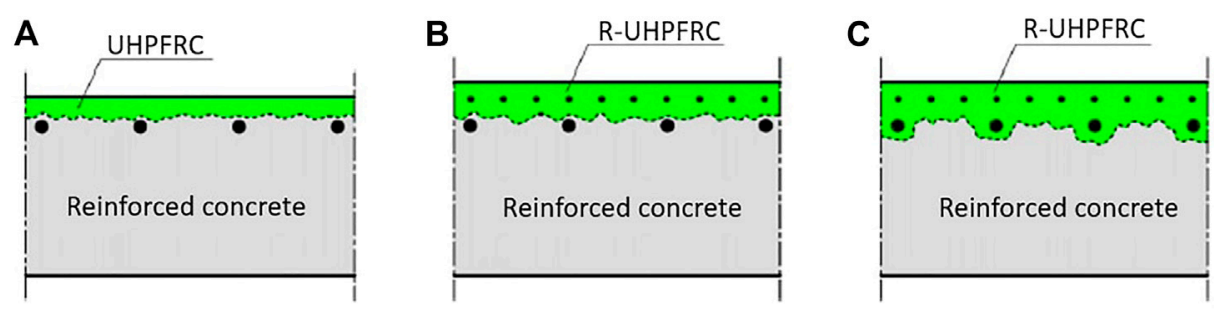

FIGURE 3 | Typical configurations of structural elements combining UHPFRC and reinforced concrete. (A) UHPFRC layer has a protective function only; (B) R-UHPFRC layer has a structural resistance as well as a protective layer; (C) R-UHPFRC used for rehabilitation of corrosion damage of existing rebars. Adapted from (Denarié and Brühwiler, 2006).

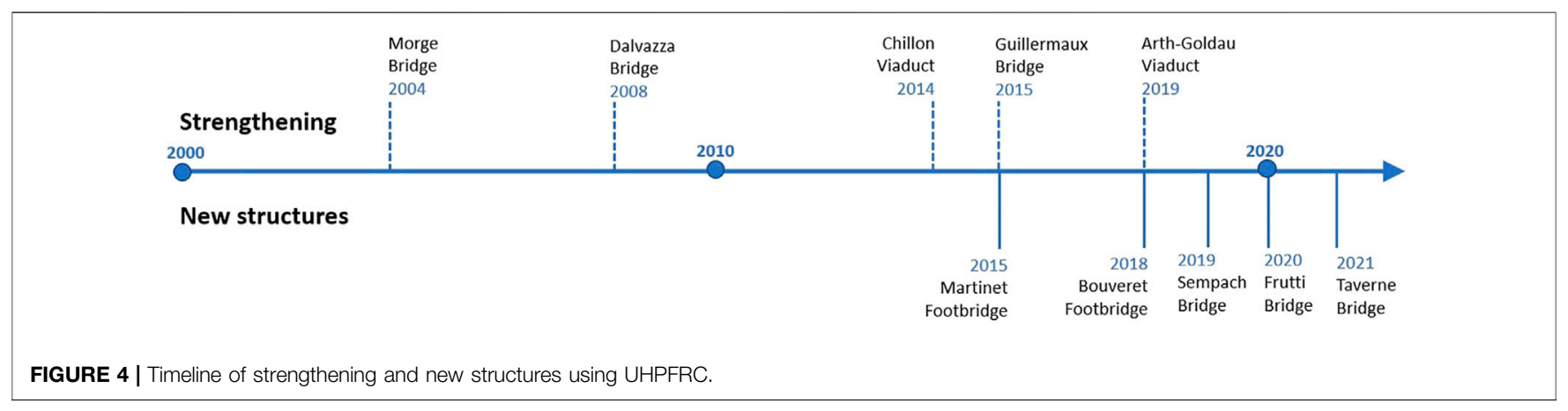

(Brühwiler, 2016a). Another type of UHPFRC application is the reinforcement of highway viaducts such as the Chillon Viaduct (Brühwiler, 2020).

New structures using UHPFRC have been built since 2013, and these applications are presented in New Designs section. Besides the competitive costs of these structures, a key aspect of the use of UHPFRC in new structures is the new possibilities in element shapes aesthetic that UHPFRC offers. Designed directly in partnership with the MCS, the Martinet Footbridge opened the doors for a new generation of footbridges, such as the Bouveret Footbridge. Moreover, the first railway (Sempach Bridge) and road (Taverne Bridge) bridges made of UHPFRC in the country have been recently built. Additionally, UHPFRC has been combined with timber (Fruttli Bridge). This composite structure shows promising results in terms of sustainability.

Besides the applications mentioned above, many other projects have been built throughout Switzerland. Figure 5A presents a map of the UHPFRC applications in Switzerland. More than 280 applications have been realized between 2003 and 2021. A database of UHPFRC application is provided on the laboratory website (MCS, 2021).

Statistics on the number of applications per year (Figure 5B) and volume of UHPFRC per year (Figure 5C) show a significant increase in applications since 2013. Two main catalysts explain this trend. First, an industrial premix has been commercialized in 2013 (Holcim710), allowing easy use of UHPFRC by construction companies. Then, the technical leaflet SIA 2052 (Swiss Society of Engineers and Architects, 2016) was introduced in 2016 and presents the state of the art of UHPFRC knowledge based on research findings to practicing engineers. Besides material properties, this leaflet also includes the concept of enhancing existing RC structures and quality control procedures. This structural code has provided key support to engineers, enabling the democratization of UHPFRC in the Swiss construction sector.

\section{Strengthening of Existing Bridges \\ First Application-Morge Bridge}

The first bridge application of UHPFRC in Switzerland was the rehabilitation of a short-span bridge over La Morge River nearby Sion (Figure 6) (Denarié and Brühwiler, 2006). The 10-m-span bridge has been widened, strengthened, and the deck rehabilitated in three steps (Figure 6C). First, the bridge has been widen by adding a fifth RC beam and the downstream curb has been replaced with a prefabricated element in UHPFRC. Then, the upper surface of the deck has been replaced by a 3-cm layer of UHPFRC as the concrete was contaminated with chlorides. Finally, a protective layer of UHPFRC has been used to replace the surface concrete on the upper-stream curb for the same reason.

The fresh self-compacting UHPFRC material was prepared at a local concrete prefabrication plant and then brought to the site by a truck and poured on the hydro-jetted deck surface (Figure 6B). The bituminous pavement was applied on the UHPFRC surfaces after 8 days of moist curing. The bridge was reopened to traffic 1 month after the beginning of the construction work, and it was thus a faster intervention than traditional RC techniques that already require 28 days of curing.

The UHPFRC mix was the first application worldwide of the CEMTEC $_{\text {multiscale }}$ developed at the LCPC in Paris (Rossi, 2002). 


\section{UHPFRC applications since 2003}

\section{$9730 \mathrm{~m} 3$ since 2003}

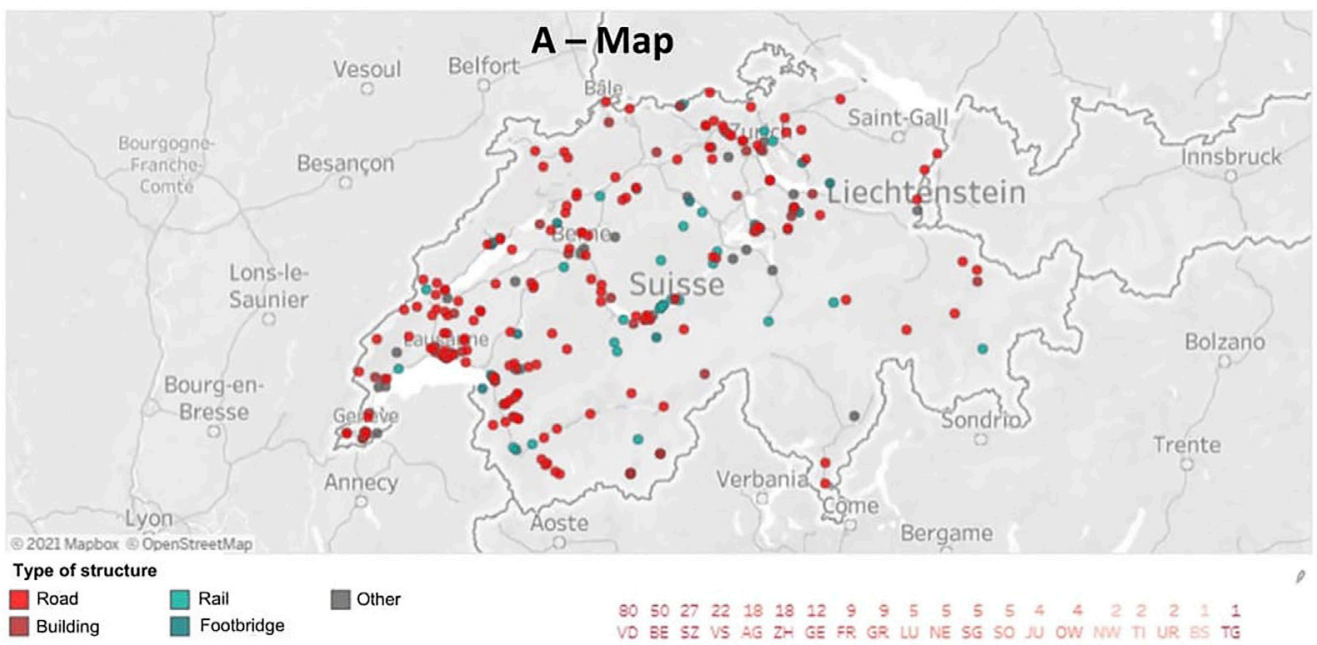

B - Application per year

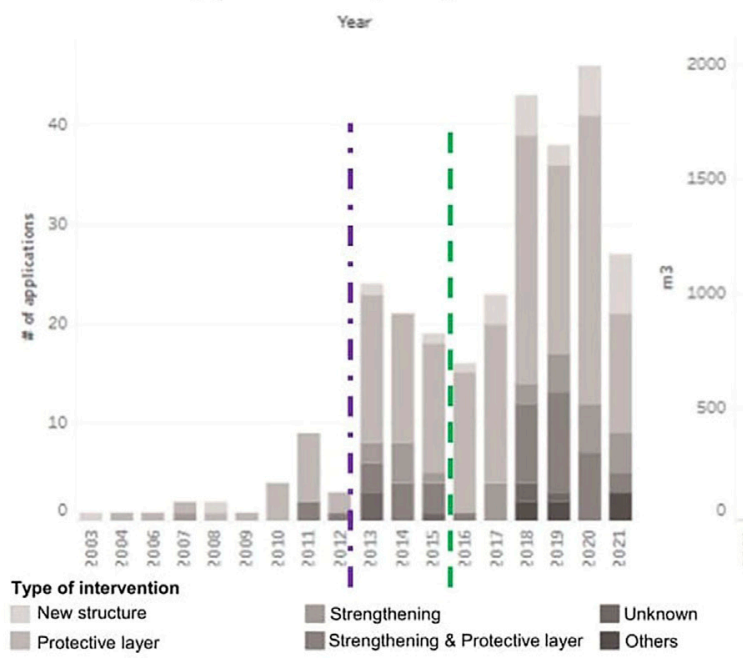

C - Volume per year

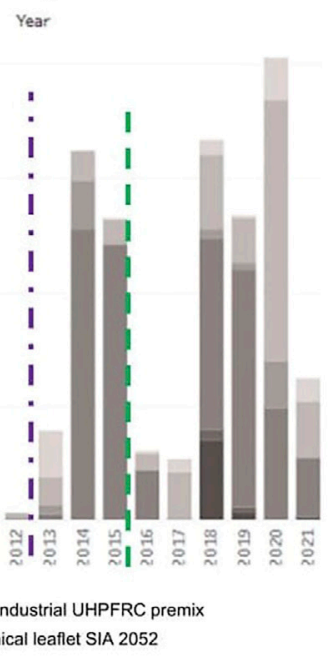

FIGURE 5 | (A) map of UHPFRC in Switzerland; (B) Histogram of applications per year; (C) Volume of UHPFRC used per year.

This mix was tailored for this application in the laboratory of MCS at EPFL. The mix contained $1430 \mathrm{~kg} / \mathrm{m}^{3}$ cement, microsilica, fine quartz sand with a maximum grain size of $0.5 \mathrm{~mm}$. The microsilica/cement and water/binder ratio were 0.26 and 0.125 , respectively. The reinforcement of this matrix was provided by a mix of microfibers (steel wool of $2-3 \mathrm{~mm}$ length) and macro fibers of $10 \mathrm{~mm}$ length and an aspect ratio of 50 , with a total dosage of $706 \mathrm{~kg} / \mathrm{m}^{3}$ (or $9 \mathrm{vol} \%$ ) (Denarié and Brühwiler, 2006).

Uniaxial tensile tests have been performed on dogbone specimens in the laboratory at EPFL to guarantee that the UHPFRC has the required properties (Denarié and Brühwiler, 2006). These specimens have been cast on-site during interventions. Remarkable properties have been observed, such as tensile stress of $14 \mathrm{MPa}$ and an average maximum tensile deformation in the strain-hardening domain of $1.5 \%$. The average compressive strength and modulus of elasticity were respectively
$182 \mathrm{MPa}$ and $47 \mathrm{GPa}$. Additionally, permeability tests using the torrent method have been performed on-site (Denarié et al., 2005), showing the extremely low permeability or the UHPFRC layer about 30 times lower than traditional concretes. The UHPFRC protective properties have been assessed after 10 years of service (Denarié and Brühwiler, 2015). Although a severe exposure to de-icing salts has been observed, the chloride penetration in the UHPFRC was shallow, validating the high durability of this protective layer.

This first application shows the importance of the dialogue between academia and the industry to enable innovations in the construction sector. Thanks to the involvement of the MCS laboratory in designing the intervention and preparation of the UHPFRC mix, this first application was made accessible to the engineers and construction companies. Additionally, validations of the application through laboratory and on-site tests have provided solid practical evidence of the theoretical 

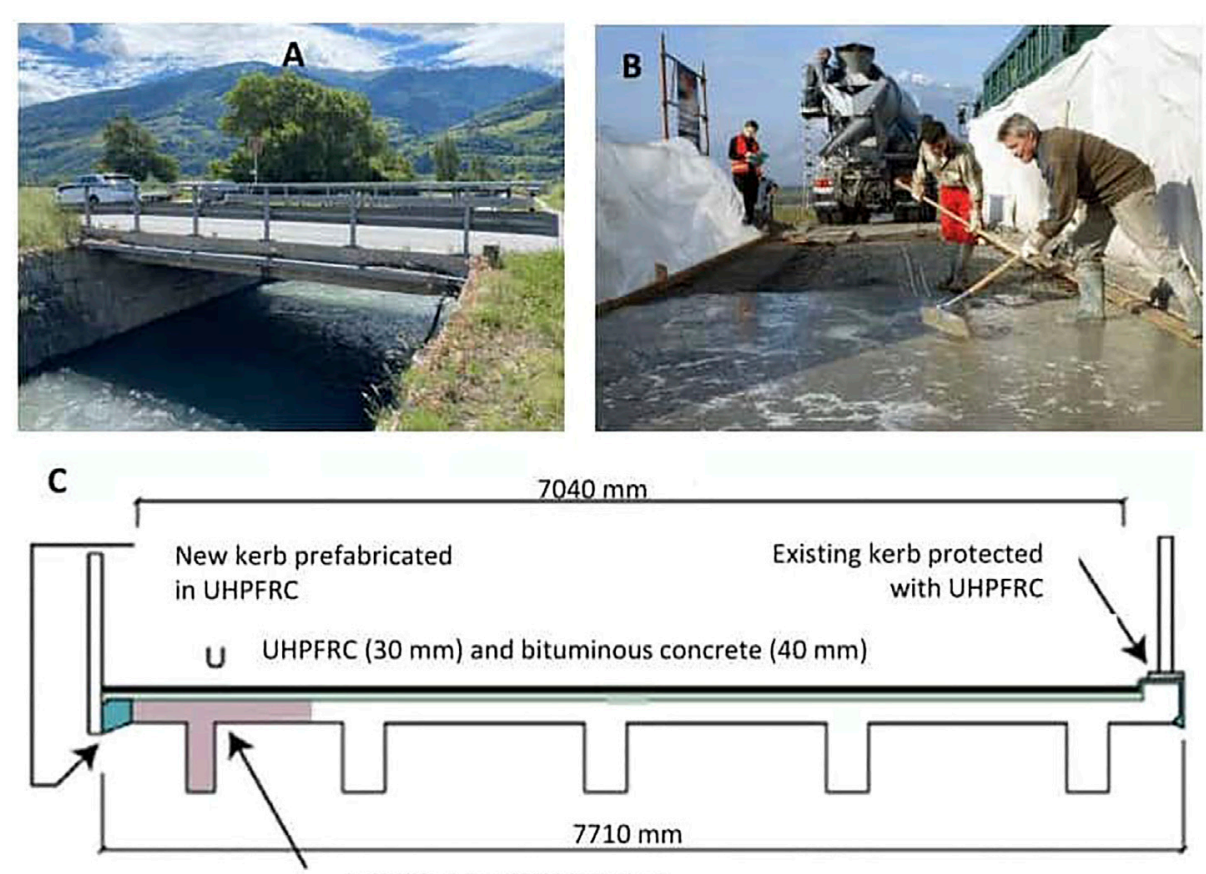

New beam prefabricated in reinforced concrete

FIGURE 6 |Bridge over La Morge river. (A) Photograph of the bridge 18 years after the intervention (Photo N. Bertola); (B) UHPFRC pouring (Photo A. Hertzog); (C) scheme of the intervention using UHPFRC.

advantages of the UHPFRC Technology for structural strengthening.

\section{Rehabilitation of Historical Monuments}

The Dalvazza Bridge is the only bridge in reinforced concrete built using Vierendeel girders in Switzerland (Figure 7). This structural system consists of the upper and lower chords, between which vertical posts are inserted, providing a unique aesthetic to this bridge designed in 1924 by the engineer Nicolaus Hartmann (Conzett, 2008). In 2008, the bridge showed severe frost damage. Heavy industrial vehicles have also caused significant damage, showing a lack of structural capacity of the bridge (Holcim, 2011). The repairs were limited to the necessary minimum to keep the original aspect of this historic structure.

The frost-damaged areas on posts have been replaced with shotcrete and sealing. A reinforcement of the slab has been made using the R-UHPFRC layer with $3 \%$ of fibers. This layer has a thickness between 20 and $80 \mathrm{~mm}$ and has several purposes. First, it improves the structural performance of the slab. Then, it works as a protective layer for the existing reinforcement and secondary layer. Finally, this layer is used as road pavement, as chippings have been included in the upper part of the layer.

As the UHPFRC layer has multiple purposes, the UHPFRC Technology has significantly reduced the length of the intervention. The rehabilitation costs have thus been significantly lowered, and the original aspect of this historical structure have been maintained. This intervention shows that the aesthetic of a bridge can be preserved while the bridge structure is enhanced with competitive intervention costs using the UHPFRC Technology.

Since the intervention, inspections have been made, such as by the authors in 2021. They have revealed few damages on the risers that have been rehabilitated using traditional methods. On the other hand, the R-UHPFRC layer does not present any cracks or signs of degradation. These observations show that interventions made with UHFRPC show better durability than traditional concrete interventions. An intervention made uniquely of UHPFRC would have thus been more appropriate and is nowadays recommended.

The Guillermaux Bridge spans the Broye River in Payerne and was built in 1920 (Figure 8). It has a two-lane carriageway and two sidewalks. This bridge is among the first reinforced concrete bridges in Switzerland. Its static system is a threehinged arch with a span of $28 \mathrm{~m}$. Besides its technical characteristics, the various ornaments (the four obelisks) and the decorations on the facings are remarkable. For these reasons, the structure has earned the status of a historical monument.

The Guillermaux Bridge has never been waterproofed. The road water and de-icing salts have penetrated the structure's concrete for almost a century. Despite the damaged state of some load-bearing elements and several alarming expert reports suggesting the immediate replacement of the structure, the population and the local authorities have refused to demolish the bridge because of its outstanding importance in the urban landscape. Due to the requalification of the Guillermaux road, the 

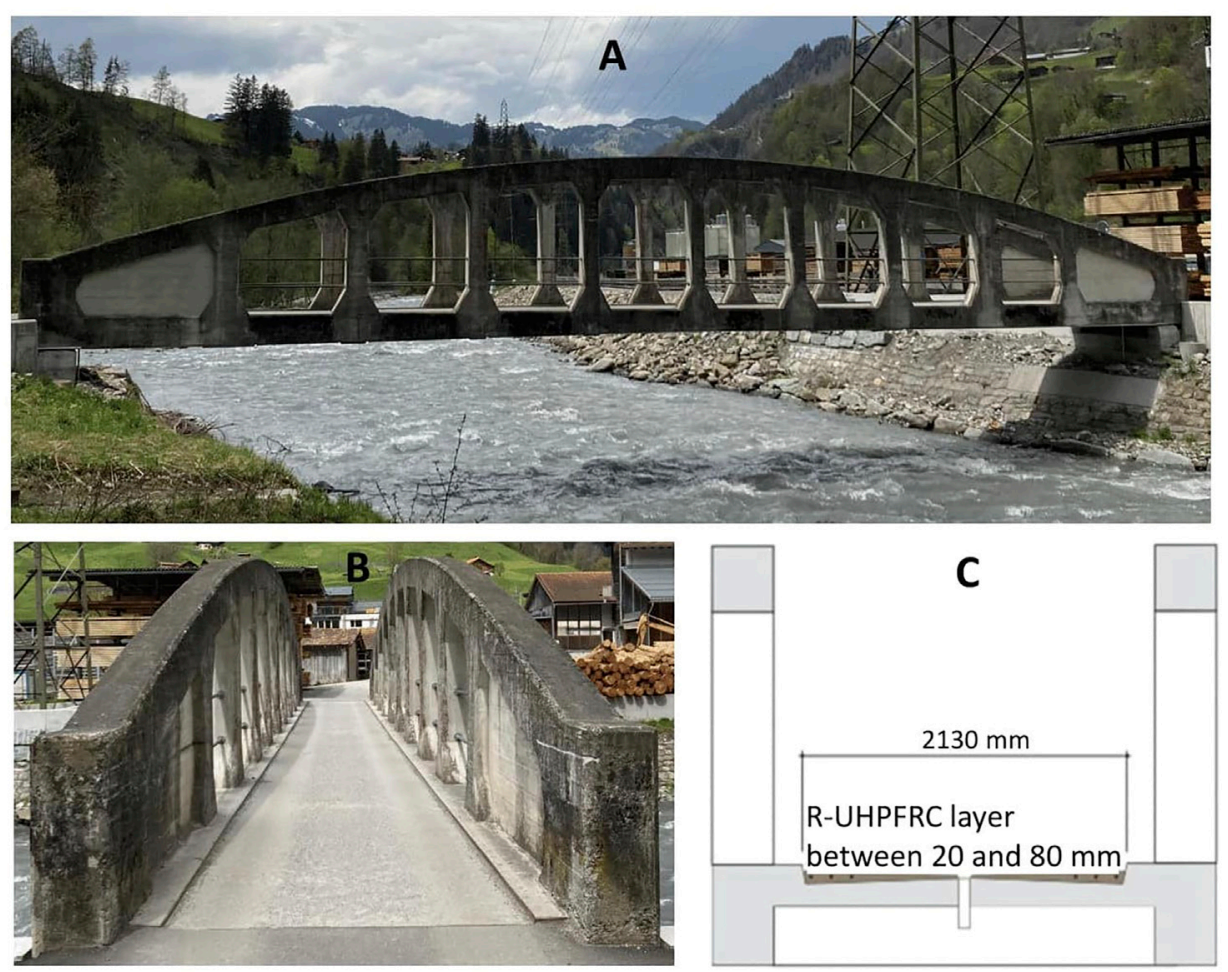

FIGURE 7 | Dalvazza Bridge rehabilitated in 2008. (A), (B) Photographs of the Vierendeel structure in 2021 (Photo P. Schiltz); (C) intervention with R-UHPFRC.

bridge should also carry out exceptional convoys, increasing the load requirements for this structure.

In 2015, an intervention was performed to enhance the structural capacity and rehabilitate the damaged deck to extend the structure use span (Brühwiler, 2016a). The application of a 50-mm layer of R-UHPFRC has enabled to lock the hinge on the arch crown as well as fixing at both bridge ends a tensile membrane in the new transition slabs (anchored in the ground). This modification of the static system did not have any visual impacts. It allowed a considerable reduction in bending stresses and better use of the concrete compressive strength of the central arch. The increase of capacity has thus been significant (up to 60\%). The waterproofing quality of UHPFRC also protects the deck against the action of water and de-icing salts. Finally, particular care was taken to restore parapets with their decorative elements. As a preventive measure, a hydrophobic impregnation against water penetration was placed on the bridge deck.

These interventions help preserve the original aesthetic quality of the bridge as well as improving its structural capacity. Soft interventions, relying on UHPFRC Technology, have the potential to rehabilitate existing bridges with adequate respect to cultural and aesthetic values.

MCS was actively involved in the rehabilitation of the Guillermaux Bridge. First, MCS made expertise on the condition assessment of the existing structures following the recently introduced Swiss standards for existing structures (Swiss Society of Engineers and Architects, 2011). Then, the laboratory proposed the intervention concept and was actively involved in the design of the intervention (structural assessment, development of the adequate UHPFRC mix). This case study is a typical example where traditional strategies would have led to replacing the structure, increasing the project costs and environmental impacts significantly.

\section{Landmark Viaducts}

Several landmark viaducts have been rehabilitated in Switzerland using UHPFRC Technology since 2014. The main criteria to design interventions were the structural efficiency, durability, relatively low intervention costs and economic efficiency. Two examples are shown below: The Chillon and Arth-Goldau viaducts.

The Chillon viaducts are two parallel post-tensioned concrete highway structures built in the late 1960s (Figure 9). These viaducts are $2120-\mathrm{m}$ long with a width of $13 \mathrm{~m}$. These bridges needed to be strengthened to guarantee structural safety for future demands.

A layer of R-UHPFRC has been cast on the deck (Brühwiler et al., 2015). This layer is $50-\mathrm{mm}$ thick and includes $12-\mathrm{mm}$ diameter rebars spaced at $125 \mathrm{~mm}$. A bituminous pavement with an overall thickness of $80 \mathrm{~mm}$ has been placed on the UHPFRC surface. First, the box-girder bending resistance has been significantly enhanced longitudinally (up to 20\%). Then, the stiffness and ultimate resistance of the slab were increased to reduce fatigue stresses in existing steel rebars and to increase significantly the ultimate bending and shear resistance of the slab. 

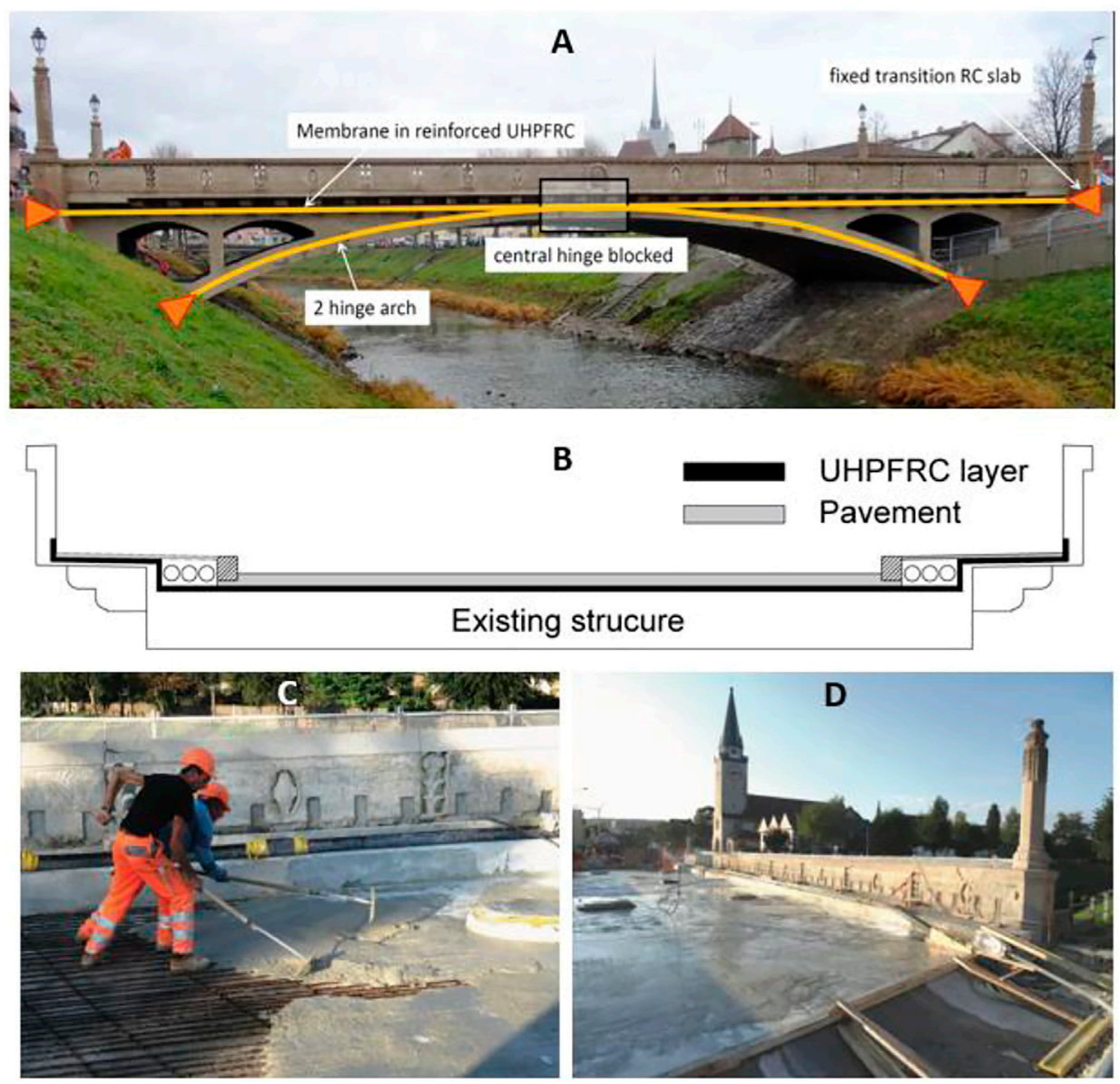

FIGURE 8 | Guillermaux Bridge. (A),(B) static system and intervention; (C),(D) Photographs of the pouring UHPFRC (Photograph A. Herzog).

Finally, the UHPFRC acts as a waterproof layer to improve durability.

The 1150 cubic meters of UHPFRC were cast over in less than 30 working days per viaduct in 2014 and 2015, respectively. This relatively quick execution has been possible by using a casting machine specially developed by the contractor for this intervention (Figure 9C). The overall cost of the intervention was $200 \mathrm{US} \$ / \mathrm{m}^{2}$ which were about five times lower than traditional strengthening methods (Brühwiler, 2020). Additionally, the duration of the construction intervention was much shorter compared to traditional methods, limiting the impacts for the highway users.

The MCS laboratory has also been actively involved in this application. The laboratory contributed to the conceptual design of the intervention, definition of the UHPFRC mix and tendering documents as well as quality control during works. Full-scale failure tests to evaluate the transverse punching-shear resistance of the RU-RC slab were performed (Zwicky and Brühwiler, 2015) and validated with numerical models (Sadouki et al., 2015). Recently, long-term monitoring data were collected to increase understanding of the global behavior of the strengthened structures, such as environmental and operational loads
(Martín-Sanz et al., 2020) and fatigue stress levels (Sawicki and Brühwiler, 2020). These studies have validated the intervention concept with UHPFRC Technology.

This example is one of many examples showing that UHPFRC interventions are cost-effective which is actually the main reason for the high number of applications of the UHPFRC Technology in Switzerland. In addition, the preservation of cultural and aesthetic values does not necessarily mean higher costs of interventions. Advanced structural engineering methods, such as UHPFRC Technology, are thus necessary for effective and sustainable infrastructure management.

The second example involves the rehabilitation of three highway twin viaducts of identical construction. These 45year-old structures follow each other close to Arth-Goldnau in Central Switzerland. The total length of all viaducts is $1050 \mathrm{~m}$.

The viaduct superstructure is composed of four slender precast prestressed girders (Figure 10). RC girders have lengths of about $40 \mathrm{~m}$ and are designed as simply supported beams. However, they were monolithically joined over the piers during the construction, avoiding construction joints. The structure thus behaves as a continuous beam with a significant bending moment over the support. Due to the design of the girder as simple beams, the 


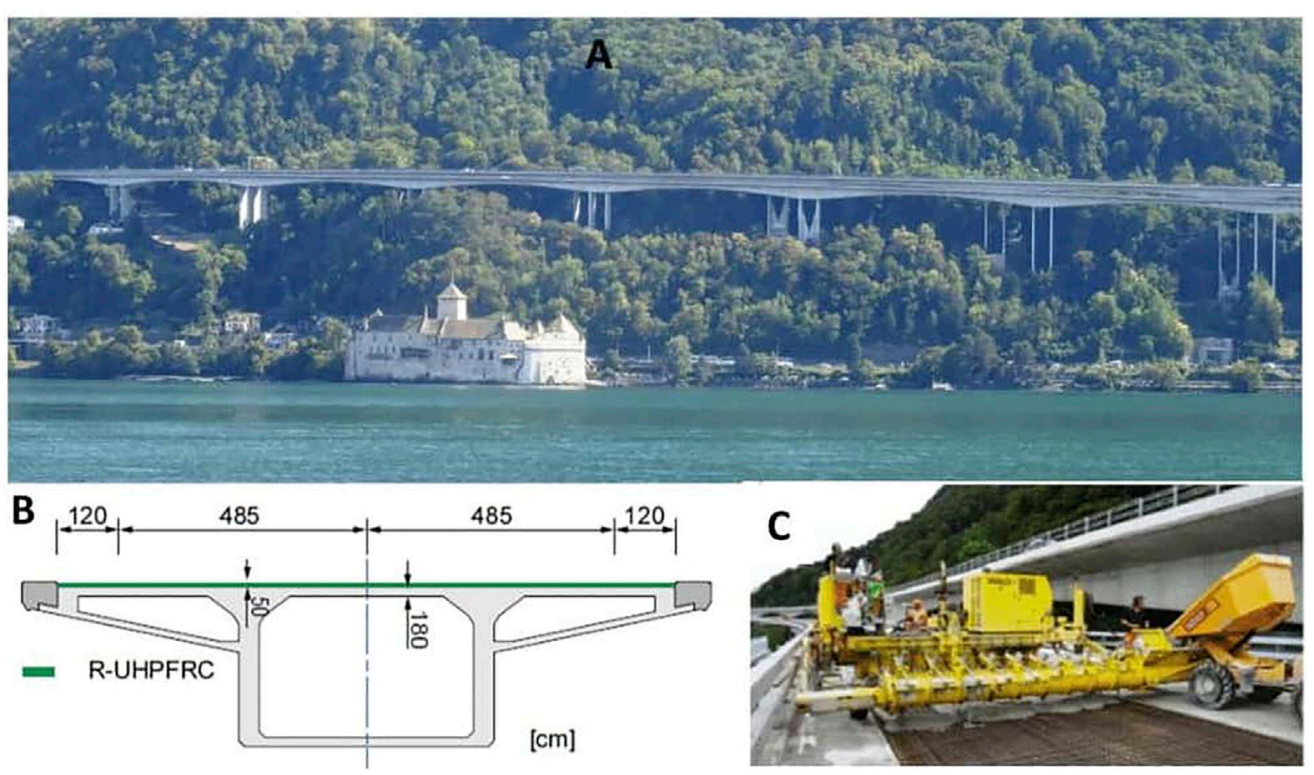

FIGURE 9|Chillon Viaduct. (A) Overview of the viaduct above the Leman Lake and Chillon Castle; (B) cross-section of the bridge and the intervention; (C) UHPFRC casting (Photographs: E. Brühwiler).

initial hogging moment capacity of these girders was relatively low. The structure is thus structurally deficient, and these viaducts must be strengthened to increase the load-bearing capacity. The viaducts also needed to be rehabilitated due to the significant rebar corrosion on rebars of outer girder webs.

To improve hogging moment capacity, a layer of $100 \mathrm{~mm}$ of R-UHPFRC on top of the deck has been including two layers of rebars spaced every $100 \mathrm{~mm}$ with a diameter of $20 \mathrm{~mm}$. This capacity increase allows a plastic moment redistribution from the midspan sagging to the supports at the ultimate limit state. This moment redistribution requires that the sections have sufficient ductility to enable the formation of plastic hinges. This condition has been verified in using structural FiniteElement analysis accounting for non-linear material behavior (Sadouki et al., 2017). This R-UHPFRC layer is extended by $6 \mathrm{~m}$ on each side to increase the shear resistance of the girder. The remaining area of the deck slab is strengthened by a $45 \mathrm{~mm}$ thick UHPFRC layer with rebars in the transverse direction in order to increase the torsional stiffness of the cross-section, improving the distribution of wheel loads between the girders. The UHPFRC layer also acts as waterproofing protection for the RC structure. In addition, UHPFRC is used to rehabilitate local rebar corrosion damage on the outer girders and bottom flanges. The UHPFRC has been cast on the three viaducts (one direction) in 30 working days for a total of 1300 cubic meters of material.

MCS has helped in the design of the intervention by providing the structural-strengthening concept and its numerical validation. The use of UHPFRC was technically more effective both in terms of material use and construction time (Methner and Müller, 2019). The intervention was also significantly more economical compared to a traditional solution. In the last two applications, the suitability of the UHPFRC Technology for the rehabilitation of large highway viaducts has been validated. These examples show the potential of UHPFRC Technology for costeffective and structurally efficient infrastructure management.

\section{New Designs \\ Footbridges}

Besides its application for structural rehabilitation, UHPFRC has also been used as a material for new structures. Due to its mechanical properties, it offers new aesthetic perspective, especially for the design of footbridges where more freedom is possible.

The Martinet Footbridge is the first new design made of UHPFRC in Switzerland (Figure 11). This footbridge is located in Lausanne and has been built in 2015. The structural system is a simple prestressed girder with an asymmetric U-shape with a span of $15.3 \mathrm{~m}$ resting on RC abutment walls (Robyr et al., 2015). The footbridge is characterized by an alveolar (or "organic") parapet, enabling users to perceive that original material. The dark color was obtained by adding black pigments to the fresh UHPFRC mix. The parapet is inclined outwards, offering a feeling of space and comfort for users. The total weight of the structure is about 15 tons.

The project aims to design a slender R-UHPFRC structure with an original aesthetic (Brühwiler, 2018). The footbridge is composed of 9 precast elements arranged on-site using a light scaffold and post-tensioned a few days later. Due to the strainhardening behavior of UHPFRC, the structure remains crack-free under service conditions. Therefore, the severe requirements of Swiss standards regarding durability are fulfilled without particular measures, considerably reducing long-term maintenance costs compared to RC structures. 

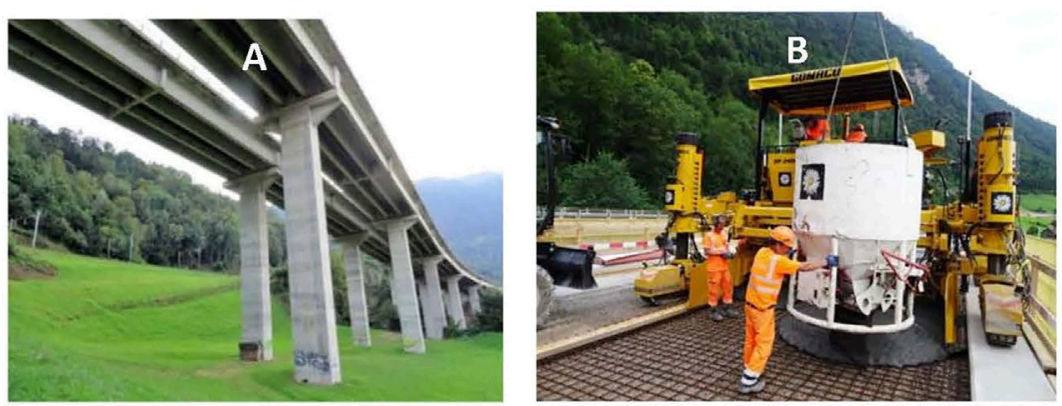

C

1. R-UHPFRC increasing bending resistance and waterproofing (2xø20@100mm)

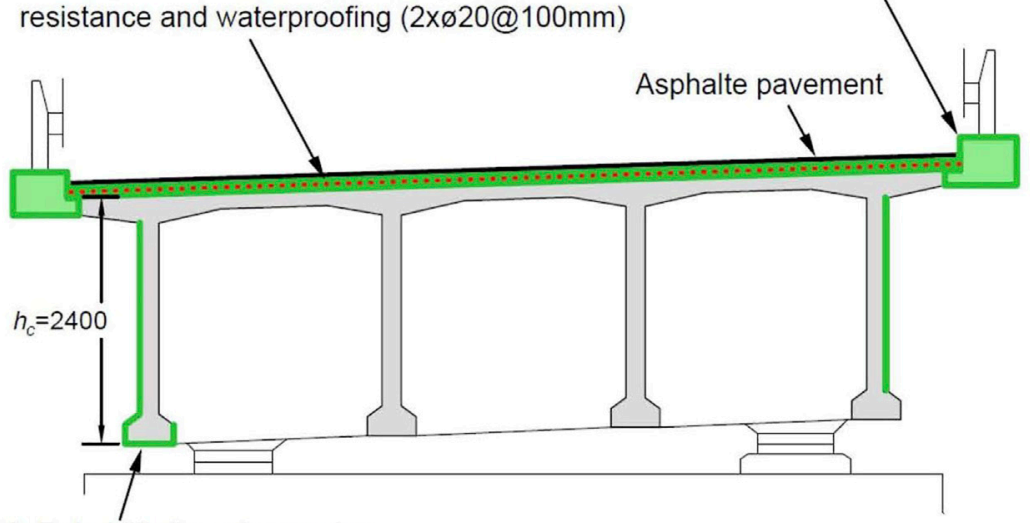

3. Rehabilitation of corrosion damaged zones using UHPFRC

rebars

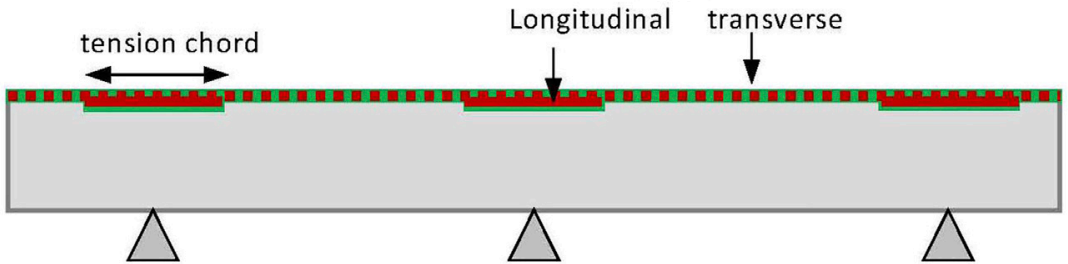

FIGURE 10|Rehabilitation of the Arth-Goldnau Viaducts. (A) Photograph the first twin viaducts (Photograph: E. Brühwiler), (B) UHPFRC casting (Photograph: A. Weykeystone), (C), (D) schemes of the interventions.

Total construction costs were approximately 3'200 US $\$ / \mathrm{m}^{2}$ of walkway surface (Brühwiler, 2018). Estimated costs for a RC footbridge were only about 10\% lower, but this traditional structure would have higher maintenance costs due to its limited durability. The cost of UHPFRC material was only $5.5 \%$ of the total costs, while the prefabrication labor and the construction of the mold were the most significant part of these costs.

As it was the first application of UHPFRC for a new bridge structure in Switzerland, the validation by testing was important for the success of the project. Three main aspects needed validations: 1) casting procedure, color and surface finish to guarantee the aeshetics; 2) fracture tests on a prototype segment to verify the design and dimensioning; 3) in-situ load tests using a 5-ton vehicle to provide valuable information about the structural behavior (Figure 11E).

A transverse bending test of the slab was performed by applying two-point forces via two vertical jacks at the center of the slab, and the slab deformation was monitored (Figure 11D). A maximum force of $138 \mathrm{kN}$ was measured for a vertical deflection of $90 \mathrm{~mm}$. This force is $50 \%$ higher than the design calculations of structural resistance. A horizontal bending test of the organic parapet guardrail was made by applying a point force against the top chord using a horizontal jack. This test aims to simulate the pedestrian thrust against the bridge guardrail. Displacement sensors were placed on the guardrail. All these laboratory tests showed a satisfactory behavior of the crosssection, beyond code requirements. During in-situ load testing, 


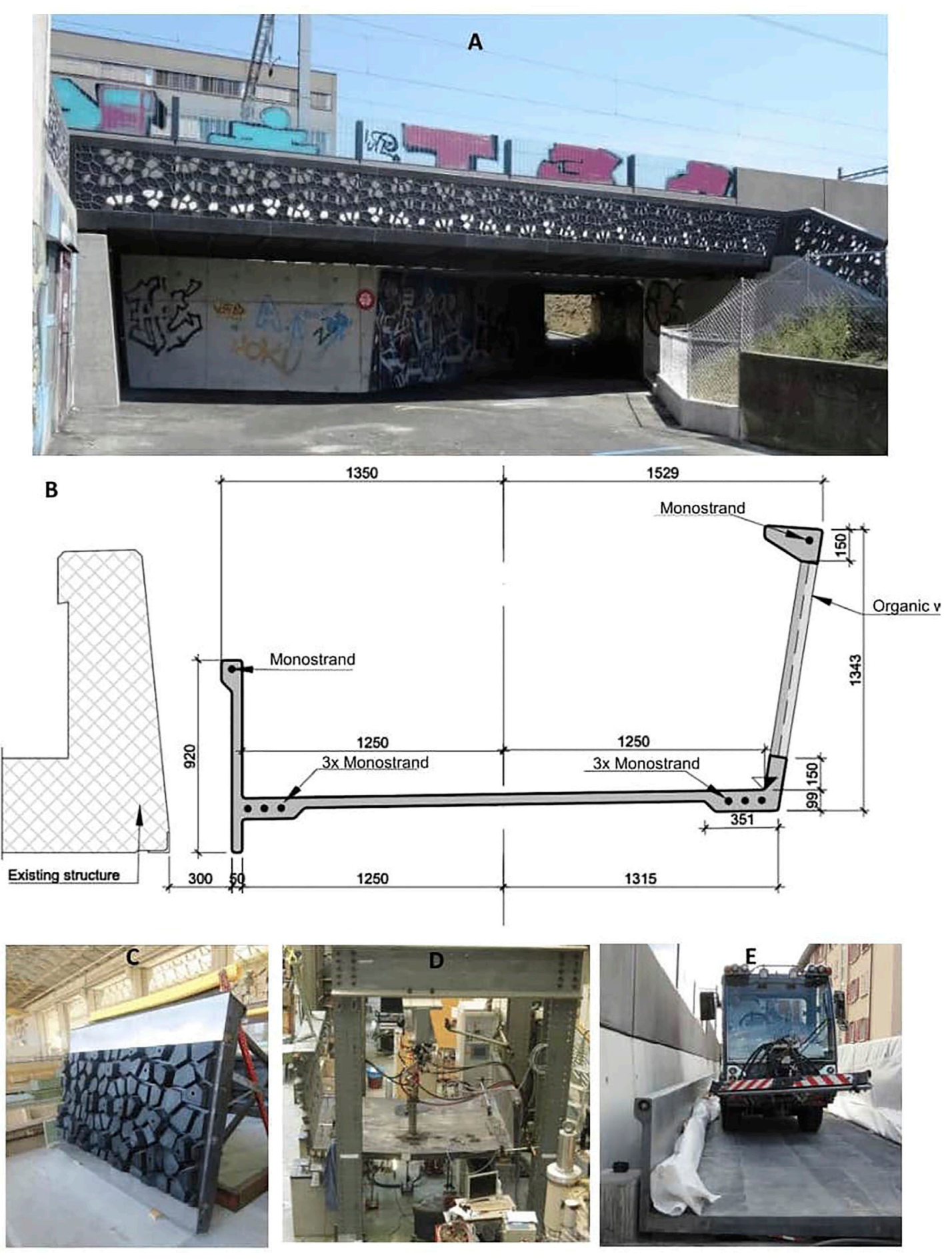

FIGURE 11 | Martinet footbridge. (A) Photograph of the footbridge; (B) Drawing of section. (C) Mold for the organic web of the Martinet footbridge; (D) laboratory test on the deck; (E) in-situ load test. (Photographs: E. Brühwiler).

the measured first frequency was $6.6 \mathrm{~Hz}$, matching the calculated value of a relatively stiff structure (Brühwiler, 2018).

This first application would not have been possible without the collaboration between MCS and the industrial partners both in terms of optimized structural design, element castings, and fullscale validation. This example shows the importance of a dialogue between academic researchers and pioneer industrial partners to apply innovative technologies in the construction industry. Due 


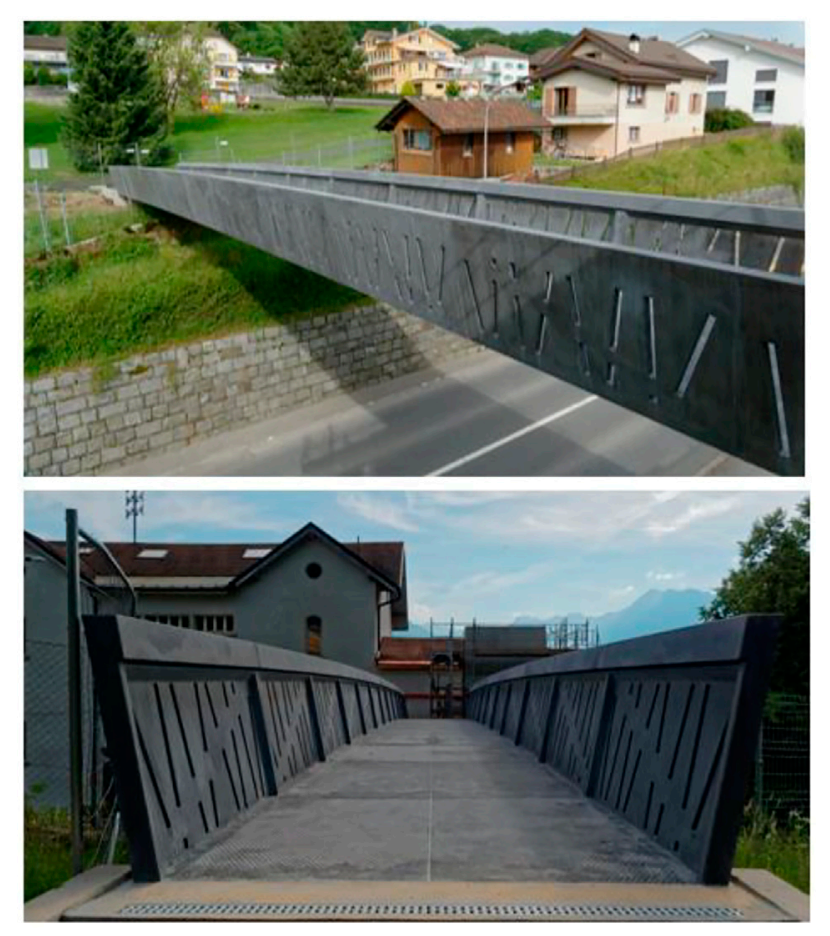

FIGURE 12 | Bouveret footbridge. (Photographs: P. Schiltz).

to its aesthetic quality and relatively simple static system, the Martinet footbridge has inspired structural engineers. Several new footbridges have been built or are under construction on the same concept in Switzerland.

The Bouveret footbridge is one example of these new UHPFRC footbridges (Figure 12). This footbridge is located in Le Bouveret adjacent to the entry of the Rhone River into Leman Lake in Switzerland. The U-shape cross-section enables an efficient structural design as prestress tendons are included in the rail guards, minimizing the overall use of material. This structure is a flyover bridge on the main road of the village. The main reason for the choice of UHPFRC as the primary structural material is the aesthetic expression of the footbridge and a lower estimated cost than a traditional structure (Brühwiler, 2018).

The UHPFRC structure has a single span girder of $26.5 \mathrm{~m}$ span. It is composed of precast segments post-tensioned longitudinally to form the monolithic structure, similar to the Martinet Footbridge. Several simplifications have been made to reduce construction costs, such as designing symmetric crosssections and a simplified web design to simplify the mold, reducing the casting costs. The precast elements were fabricated and assembled in the factory, avoiding the use of a scaffold. The whole girder was then transported to the construction site (distance of $80 \mathrm{~km}$ ). The structure was finally lifted and placed by two cranes.

Although the MCS was still involved as an expert in the conceptual design and dimensioning for this structure, the role of academia was reduced in this design. By being involved in pioneer work and educating new generations of Swiss civil engineers, the role of the MCS has been fulfilled to promote UHPFRC Technology as an alternative to traditional concrete, steel and timber structures. While providing cost-effective designs, UHPFRC has an undeniable visual quality that is appreciated by users and bridge owners.

\section{Road and Railway Bridges}

Since the pioneering works on footbridges, UHPFRC has been used as the main structural material for several road and railway bridges in Switzerland. Three of these structures are presented below. For all these structures, MCS had the role of consultant, showing that UHPFRC Technology is maturing in the construction sector in Switzerland.

The Railway Underpass Unterwalden, located in Sempach (Central Switzerland), is probably the first R-UHPFRC railway structure worldwide on a main railway line (Figure 13). MCS elaborated the initial conceptual design. This UHPFRC bridge has replaced a deteriorated RC slab structure in 2017. Due to the site constraints and railway-structure requirements, the new structure needed a small height with a significant stiffness. Due to its high mechanical properties, UHPFRC has been selected as the main structural material. A relatively stiff and lightweight structure, composed of one single span ribbed plate and one edge girder per rail, has been designed with two precast elements. This first pilot application on a small structure also provided valuable experience for future applications of the UHPFRC Technology in railway structures.

The ribbed plate consists of a $50 \mathrm{~mm}$ thick upper plate acting as a compression chord of the single-span structure with a span of $6.0 \mathrm{~m}$. Ribs are spaced by $250 \mathrm{~mm}$, and they have a thickness varying from $80 \mathrm{~mm}$ at the bottom to $100 \mathrm{~mm}$ at the top. Two 26$\mathrm{mm}$-diameter rebars are placed in each rib. Ribs have a sufficient cross-section to resist the design shear force without vertical reinforcements. No transverse diaphragm was necessary. The edge board is designed to hold back the ballasted bed of the railway and is a massive girder with important steel reinforcement to resist the impact force of under-passing vehicles.

The bridge design followed the Technical leaflet on UHPFRC (Swiss Society of Engineers and Architects, 2016), reducing the need for academic expertise in the design process. The serviceability limit state and the fatigue safety were the two critical requirements for dimensioning. The structural design was verified using two full-scale tests on girders with $\mathrm{T}$ crosssection at the Luzern University of Applied Sciences and Art (Switzerland) (Borkowski et al., 2017).

Each precast UHPFRC element was mounted in one night and put in service immediately after installation. The structural behavior was monitored to validate the engineer calculations. Conducted by the ETH Zurich (Switzerland), these monitoring campaign have confirmed that the bridge behavior is significantly stiffer than predictions obtained using numerical models and the railway load model (Brühwiler et al., 2019).

The 24 cubic meters of UHPFRC that was required to build the bridge represented only $7.5 \%$ of the construction costs (Brühwiler, 2018). Material expenses are therefore of little interest in the whole project expenses of such structures. This 

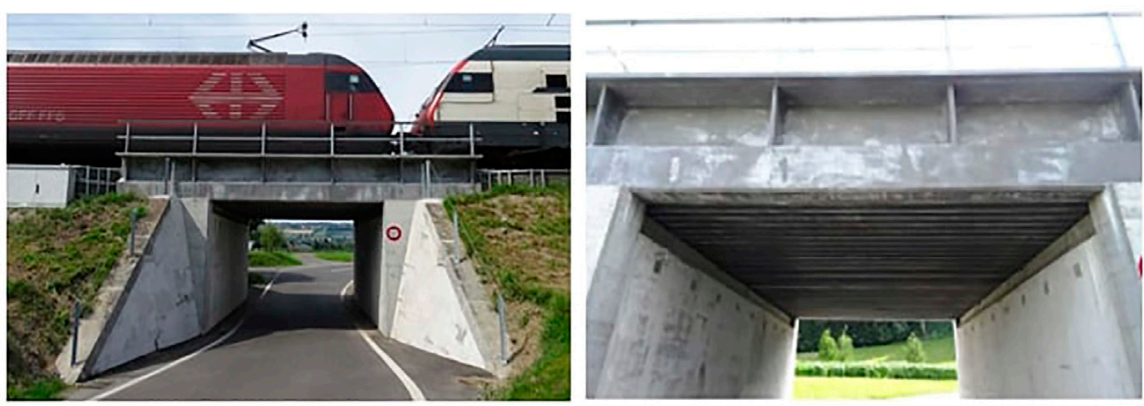

FIGURE 13 | Railway underpass Unterwalden (Sempach) with a structure in R-UHPRFRC resting on concrete abutments. (Photographs: E. Brühwiler).
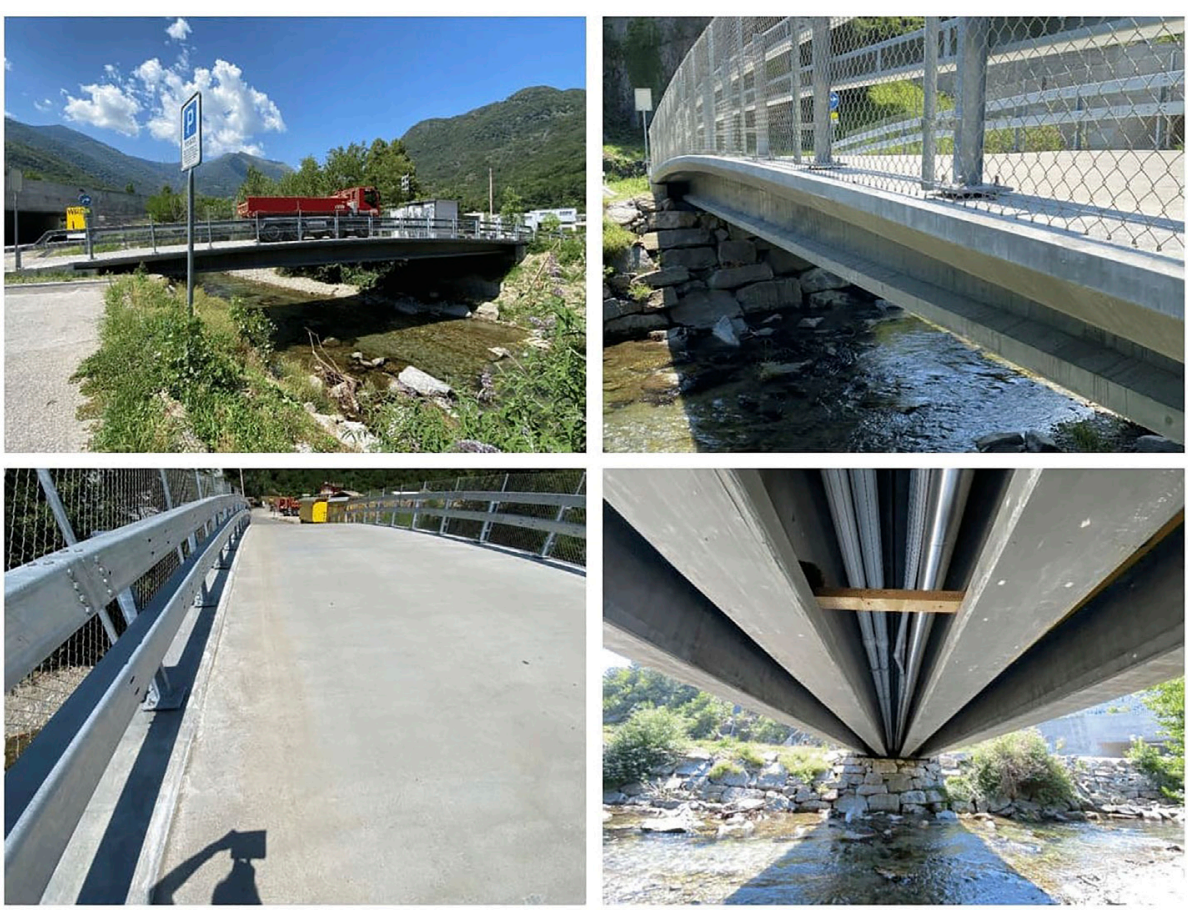

FIGURE 14 | Taverne bridge. (Photographs: E. Brühwiler).

project shows that UHPFRC is also appropriate for railway structures. The short duration of intervention was also an important criterion to select the optimal bridge design to avoid restrictions on this railway line.

The Taverne Bridge, built in 2020, is the first road bridge entirely made of UHPFRC (Holcim, 2021) (Figure 14). The conceptual design and pre-dimensioning was done by MCS. This 25-m long prestressed bridge is located on a private road of a construction company that has decided to build a showcase bridge for UHPFRC Technology (Walo, 2020).

The bridge is composed of 4 precast girders with a variable height between 750 and $1250 \mathrm{~mm}$ and they are connected by a cast-on-site $50 \mathrm{~mm}$-thick deck that serves as a roadway. The single-span bridge has been built using a semi-integral jointless structure where flexible transition plates are connected to the deck, significantly improving durability and reducing maintenance costs.

The construction company was able to manufacture the precast girders on its factory next to the bridge, avoiding the problem of the transport (26-m long beams of 40 tons). Then, they have installed them on a Friday night. The deck was poured on Saturday. After appropriate treatment, the bridge was opened to traffic on the next Monday.

Due to its structural design and construction techniques, the construction time has been significantly shortened. This case study shows that UHPFRC Technology enables the construction of a new road bridge within a few working days, limiting the impact for users to a minimum. This bridge is one of the best 

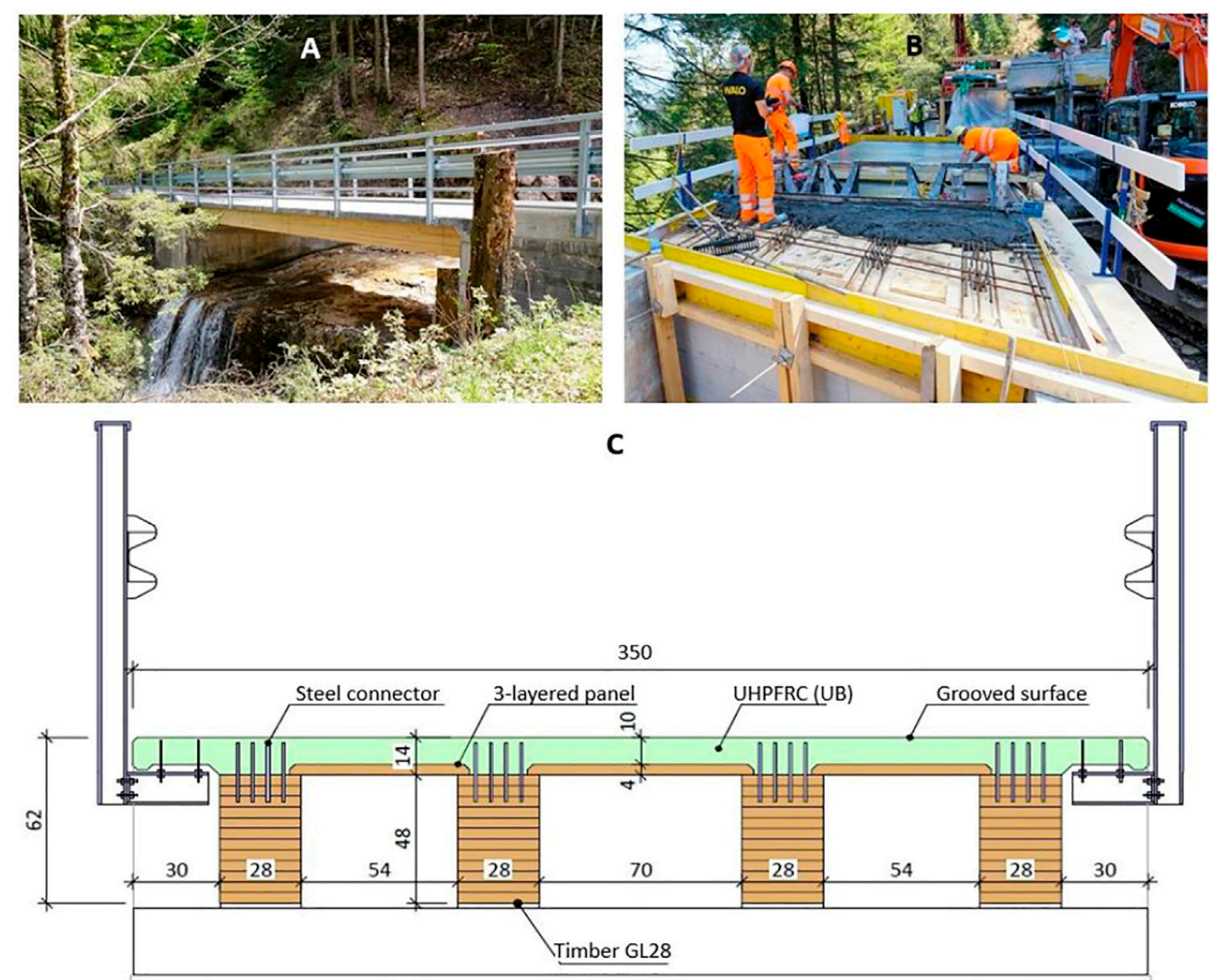

FIGURE 15 |Fruttli Bridge. (A) Photograph of the bridge; (B) pouring of the UHPFRC deck. (C) section of the composite timber-UHPFRC bridge. (Photographs: E. Kälin).

examples of the potential of UHPFRC Technology for making slender structures that are durable and can be built within a limited construction time.

The Fruttli Bridge is located near the Rigi Mountain in Central Switzerland (Figure 15). This timber-UHPFRC composite structure has replaced a 50-years-old concrete bridge that no longer met requirements in 2019 (Kälin, 2020). The static system is a single beam of $10 \mathrm{~m}$. This innovative structure was chosen due to its cheaper construction cost, better durability, and shorter construction time. After preparatory work on the existing abutments, the entire bridge superstructure was built within 1 week. The bridge was already open to traffic just 4 days later.

The main girders are made of timber, while the UHPFRC serves as a deck and protection for the timber beams. The four girders have a height of $520 \mathrm{~mm}$ high and a width of $260 \mathrm{~mm}$ and are made of glued laminated timber made of Swiss wood. The UHPFRC has been cast on-site. The slab thickness is between 86 and $140 \mathrm{~mm}$, with a longitudinal slope of $5 \%$. The shear connection between timber and UHPFRC is made through reinforcement bars.

The Fruttli Bridge is the first timber-UHPFRC composite bridge in Switzerland. It shows that this type of construction can compete with a traditional concrete structure in terms of price. Compared to a traditional concrete bridge, this solution has been estimated to have halved the $\mathrm{CO}_{2}$ emissions. In addition, roughly the same amount of $\mathrm{CO}_{2}$ is permanently stored in the wood as was emitted during UHPFRC production (Kälin, 2020).

\section{COMPARISON TO TRADITIONAL SOLUTIONS}

UHPFRC show significantly higher compressive and tensile strengths compared to concrete (Section 2). Consequently, the tensile strength is typically taken into account in the design of UHPFRC structures. A strengthening layer or a new element made of UHPFRC is thus significantly more slender than traditional RC design, enabling an important reduction of the structural dead weight. The UHPFRC Technology allows for the smaller intervention of existing structures (Morge bridge, Chillon Viaduct) than would have been required with traditional RC strategies (often involving invasive and thus high cost destruction-reconstruction solutions).

Although concrete is a cheap material compared to UHPFRC, the overall cost of a UHPFRC strengthening intervention on existing structures is significantly lower when compared to a traditional retrofitting solution. In most countries, material costs are significantly lower than labor costs. Additionally, an important reduction of the duration of the works is possible with UHPFRC Technology, lowering the indirect costs and 
maintenance costs are reduced due to the high durability of the material. In the presented studies, total costs of the UHPFRC interventions have been significantly lower than conventional solutions. For example, traditional retrofitting solutions for the Chillon Viaduct would have been three to five times higher than the UHPFRC solution (Brühwiler, 2020).

Fast construction is of first importance when new bridges are built to replace existing structures. As UHPFRC structural elements are slender, they can often be prefabricated and assembled on-site, significantly reducing the construction time for the Taverne and Sempach Bridges. The reduction of construction costs is the main reason why numerous UHPFRC applications have already been carried out in Switzerland.

Moreover, UHFRPC Technology aligns with a sustainable development logic since the building material resources already consumed by existing structures are valorized and used much longer. The "demolish and rebuild" solutions, which are still often practiced, have a poor record from a sustainable-development perspective, even when carried out in an environmentally friendly manner. For the Guillermaux Bridge, a life-cycle assessment shows that a traditional solution would have an environmental impact 50-\% higher than the UHPFRC intervention (Hajiesmaeili et al., 2019).

The timber-UHPFRC composite structures, such as the Fruttli Bridge, offer promising results in terms of sustainable development for Switzerland. These structures combine higher durability than timber structures and smaller environmental impacts than RC structures. In addition, the timber girders can be made of local material in Switzerland, reducing transport costs and $\mathrm{CO}_{2}$ emissions.

These interventions, made with the UHPFRC Technology, are superior to traditional retrofitting solutions with concrete in terms of durability. Due to its compact matrix, low water/ binder ratio, and steel-fibres content, UHPFRC has a strainhardening behavior. Consequently, this material is waterproof, and thus interventions are durable, avoiding typical degradation mechanisms in concrete structures such as rebar corrosion and AAR.

This theoretical behavior has been validated by tests performed on the Morge Bridge in 2014 (Denarié and Brühwiler, 2015). Ten years after the interventions, chloride penetration has been observed as extremely limited. These tests show that UHPFRC behaves according to the expectations even when the material is cast on-site without thermal treatment.

Since UHPFRC interventions are not invasive or visible, the original appearance, which often defines the aesthetic quality of a concrete structure, is not disturbed. This technology is particularly suitable for intervention on heritage structures such as the Chillon Viaduct and the Dalvazza and Guillermaux Bridges.

The UHPFRC Technology offers new aesthetic expressions for footbridges that have been highly appreciated by asset managers. UHPFRC structures can be easily recognized by their slender structures, especially when U-shape sections with original parapet visuals are designed, such as the Bouveret and Martinet Footbridges. Inspired by these two examples, several footbridges are currently either under construction or under preparation, showing a strong interest of decision-makers for UHPFRC aesthetics.

\section{PARTICULAR FEATURES OF UHPFRC}

Decision-making in structural engineering is a complex process that involves multiple criteria. Besides its wellknown structural efficiency, the UHPFRC Technology shows promising results in reducing construction time and environmental impacts. Intervention costs, which are the most important decision criterion, are significantly reduced, increasing bridge-owners interest in UHPFRC technology in Switzerland in the last years. This trend is expected to continue as companies will have more experience with this new material.

Several features of the use of UHPFRC need special care. First, the workability of the material mix must be reliably mastered during casting. When complex formworks and small spacing between rebars are required, the fiber orientation may be significantly influenced (Nunes et al., 2017). In some applications in Switzerland, cracks have been shown on the UHPFRC reinforcement layer, impairing water tightness of the element. In such cases, an inappropriate mix has been used, or a inappropriate execution and curing was performed. It is thus crucial to control that the mix is has an appropriate workability, especially when thixotropic properties are required. When cracks are observed, UHPFRC structures can achieve good self-healing characteristics as UHPFRC typically has a high amount of unhydrated cementitious particles and fibers help avoid crack propagation (Garg et al., 2021). Studies (Kwon et al., 2013; Guo et al., 2019) show that the durability benefits of UHPFRC compared to traditional concrete. Additionnally, the fiber orientation and the fiber content is of primordial importance. These aspects must be accounted fore during the casting process and can be controlled by non-destructive tests (Shen and Brühwiler, 2020).

Then, structural engineers hold high responsibility for the safety of their structures. Therefore, some companies are reluctant to use new technologies that haven't shown years or decades of use without issues. Despite its well-known advantages, the UHPFRC Technology does not bypass these reluctances. Nevertheless, as many (including all largest) construction companies in Switzerland have now gained experience with UHPFRC, the authors believe that this reluctance will decrease in the future. The role of universities is also to educate new engineers on these technologies. As shown in this paper, MCS has played a crucial role in most of these applications, particularly for the first uses of UHPFRC Technology in the country. The story of UHPFRC Technology in Switzerland is an excellent example of the primordial dialogue between academia and the industry to enable innovative solutions in the construction sector. This dialogue is even more critical in the future, where the environmental footprint of the construction sector must be significantly reduced. 


\section{FUTURE RESEARCH PROSPECTS}

Several research topics must be developed further to enhance UHPFRC Technology and increase its application for structural designs and infrastructure strengthenings. Some of these aspects are detailed below.

The numerical modelling of UHPFRC structures may be particular as many softwares do not include this material, meaning that material behavior must be manually defined. As UHPFRC has a strain-hardening behavior, non-linear analysis is essential (Sadouki et al., 2017). Recommendations on modelling properly the material is given in standards, bringing confidence for reliable UHPFRC application such as reinforced and posttensioned UHPFRC structures as well as composite timberUHPFRC and steel-UHPFRC structures.

Dispite more than 20 years of international research and applications of UHPFRC, the material mix will evolve on the following aspects:

- The tensile properties shall be further enhanced to have UHFRPC with higher elastic limit combined with a strainhardening behavior by improving the bonding between the fibers and the cementitious matrix.

- Fiber orientation effect on mechanical properties as a function of workability of the fresh UHPFRC and casting procedure must be better understood.

- A low hydratation UHPFRC premix should be developed to enable the design of locally thick geometries under restraint.

- The UHPFRC workability could be improved by tailoring the material rheology.

More environmentally friendly mixes have recently been developed by replacing steel fibers with high modulus polyethylene fibers and using a low clinker content. This mix has shown promising results (Hajiesmaeili et al., 2019), reducing by $80 \%$ the environmental impacts of UHPFRC without compromising the structural properties. Additional laboratory and field tests are needed for improved understanding of the behavior of this mix. Additionally, the environmental impacts of UHPFRC interventions and new designs must be compared to conventional solutions using life-cycle assessment, such as (Sameer et al., 2019).

The behavior of structures made of or rehabilitated with UHPFRC shall be validated further through field monitoring and model-updating strategies. Monitoring on UHPFRC structures has been compared to real-structure behavior for

\section{REFERENCES}

Azmee, N. M., and Shafiq, N. (2018). Ultra-high Performance concrete: From Fundamental to Applications. Case Stud. Construction Mater. 9, e00197. doi:10.1016/j.cscm.2018.e00197

Bocchini, P., Frangopol, D., Ummenhofer, T., and Zinke, T. (2014). Resilience and Sustainability of Civil Infrastructure: Toward a Unified Approach. J. Infrastructure Syst. 20, 04014004. doi:10.1061/(asce)is.1943$555 x .0000177$ the Buna bridge (Martin-Sanz et al., 2018). Nonetheless, the bridge was monitored within the laboratory, reducing the magnitudes of uncertainties significantly. A monitoring campaign prior and after the UHPFRC intervention will help validate intervention assumptions and better understand the distribution of solicitation within UHPFRC-RC composite structures. Additionally, more non-destructive tests must be developed to better control fiber content and orientation on structural elements.

These new features could trigger UHPFRC applications in more fields such as tunnels, retaining walls and buildings (lightweight slabs). New studies on the fatigue behavior (Sawicki and Brühwiler, 2021) and hydro-abrasion (Wassmann and Brühwiler, 2016) could enable new applications in highlysolicitated road surfaces and blocks, sleepers and fixed slabs in railways structures to reduce maintenance.

\section{SUMMARY AND CONCLUSION}

This paper reviews the Swiss experience in applications of the UHPFRC Technology to enhance existing structures and design new structures. These case studies show that the use of UHPFRC is rapidly maturing in the construction industry, and many structural engineers are now familiar with this new technology. Due to its unique mechanical and durability properties, UHPFRC enables efficient structural rehabilitation both in terms of project costs, intervention time and environmental impacts. New structures made with UHPFRC lead to structural designs with unique aeshetics that are particularly appreciated for footbridges. Additionally, as most elements are prefabricated, the construction time is often significantly reduced. Timber-UHPFRC composite structures are an innovative solution for bridge design that is simultaneously sustainable, durable and cost-effective. Altogether, UHPFRC Technology offers benefits in terms of structural efficiency, economic costs, environmental impacts, and aeshetics for both existing-structure rehabilitation and new structural designs.

\section{AUTHOR CONTRIBUTIONS}

All authors provide inputs on the applications. NB, PS selected the presented applications, NB wrote the first draft of the manuscript. All authors contributed to manuscript revision, read, and approved the submitted version.

Borkowski, G., Thoma, K., Brühwiler, E., and Rupp, C. (2017). Experimentelle Validierung einer Plattenbalken-Bahnbrücke aus bewehrtem UHFB. Betonund Stahlbetonbau 112, 320-328. doi:10.1002/best.201700001

Brühwiler, E. (2018). "Structural UHPFRC to Enhance Bridges,"in Proceedings of the 2nd International Conference on UHPC Materials and Structures UHPC 2018 - China 129, Fuzhou, China, November 7-10, 2018, 140-158.

Brühwiler, E. (2016a). "Non-invasive Interventions on Three concrete Structures of High Cultural and Aesthetic Value," in IABSE Congress: Challenges in Design and Construction of an Innovative and Sustainable Built Environment, Stockholm, Sweden, September 21-23, 2016, 668-676. 
Brühwiler, E. (2016b). “"Structural UHPFRC”: Welcome to the post-concrete Era!," in International Interactive Symposium on Ultra-High Performance Concrete, July 16-18, 2016 (Des Moines, IA: Iowa State University Digital Press), 1-16. doi:10.21838/uhpc.2016.key

Brühwiler, E., Bastien-Masse, M., Mühlberg, H., Houriet, B., Fleury, B., Cuennet, S., et al. (2015). "Strengthening the Chillon Viaducts Deck Slabs with Reinforced UHPFRC," in IABSE Symposium Report (Zürich, Switzerland: International Association for Bridge and Structural Engineering (IABSE)), 1-8. Available at http://www.ingentaconnect.com/contentone/iabse/report/2015/00000105/ 00000024/art00001 (Accessed February 22, 2017).

Brühwiler, E., Friedl, H., Rupp, C., and Escher, H. (2019). Bau einer Bahnbrücke aus bewehrtem UHFB. Beton- und Stahlbetonbau 114, 337-345. doi:10.1002/ best. 201900010

Brühwiler, E. (2020). UHPFRC Technology to Enhance the Performance of Existing concrete Bridges. Struct. Infrastructure Eng. 16, 94-105. doi:10.1080/15732479.2019.1605395

Buitelaar, P., Vej, A. K., Braam, R., Kolstein, H., and de Jong, P. (2006). Reinforced High Performance concrete for Rehabilitation of Orthotropic Steel Bridge Decks," in Structural Faults \& Repair 2006 International Conference and Exhibition, Edinburgh, United Kingdom, June 2006. 19.

Cao, J., Shao, X., Zhang, Z., and Zhao, H. (2016). Retrofit of an Orthotropic Steel Deck with Compact Reinforced Reactive Powder concrete. Struct. Infrastructure Eng. 12, 411-429. doi:10.1080/15732479.2015.1019894

Charron, J.-P., Denarié, E., and Brühwiler, E. (2007). Permeability of Ultra High Performance Fiber Reinforced Concretes (UHPFRC) under High Stresses. Mater. Struct. 40, 269-277. doi:10.1617/s11527-006-9105-0

Conzett, J. (2008). Ein Vierendeel-Träger im Prättigau : die Landquartbrücke Dalvazza der Verbindungsstrasse Küblis - Strahlegg. doi:10.5169/SEALS-398906

Coufal, R., Vitek, J. L., and Kalný, M. (2016). The First Large Application of UHPC in the Czech Republic. Int. Interactive Symp. Ultra-High Perform. Concrete 1. doi:10.21838/uhpc.2016.33

Denarié, E., and Brühwiler, E. (2015). Cast-on Site UHPFRC for Improvement of Existing Structures - Achievements over the Last 10 Years in Practice and Research. Available at https://infoscience.epfl.ch/record/215013/files/ HPFRCC7_2015_ED_EB\%20.pdf.

Denarié, E., and Brühwiler, E. (2006). Structural Rehabilitations with Ultra-high Performance Fibre Reinforced Concretes (UHPFRC). Restoration of buildings and monuments $=$ Bauinstandsetzen und Baudenkmalpflege 12, 453-468. doi:10.1515/rbm-2006-6083

Denarié, E., Maître, M., Conciatori, D., and Brühwiler, E. (2005). Air Permeability Measurements for the Assessment of the in Situ Permeability of Cover concrete, 475-481.

Denarié, E., and Sajna, A. (2009). Composite UHPFRC-concrete Construction Harden Structures to Last. Baden, Austria: Austrian Society for Concrete and Construction Technology, 80-83.

Frangopol, D. M., and Liu, M. (2007). Maintenance and Management of Civil Infrastructure Based on Condition, Safety, Optimization, and Life-Cycle Cost*. Struct. Infrastructure Eng. 3, 29-41. doi:10.1080/15732470500253164

Garg, M., Azarsa, P., and Gupta, R. (2021). Self-Healing Potential and PostCracking Tensile Behavior of Polypropylene Fiber-Reinforced Cementitious Composites. J. Compos. Sci. 5, 122. doi:10.3390/jcs5050122

Graybeal, B. A. (2007). Compressive Behavior of Ultra-high-performance FiberReinforced Concrete. ACI Mater. J. 104, 146-152. doi:10.14359/18577

Graybeal, B., Brühwiler, E., Kim, B.-S., Toutlemonde, F., Voo, Y. L., and Zaghi, A. (2020). International Perspective on UHPC in Bridge Engineering. J. Bridge Eng. 25, 04020094. doi:10.1061/(asce)be.1943-5592.0001630

Guo, J.-Y., Wang, J.-Y., and Wu, K. (2019). Effects of Self-Healing on Tensile Behavior and Air Permeability of High Strain Hardening UHPC. Construction Building Mater. 204, 342-356. doi:10.1016/j.conbuildmat.2019.01.193

Habel, K., Denarié, E., and Brühwiler, E. (2002). "Structural Elements of Advanced Cementitious Materials and Concrete," in 4th International $\mathrm{PhD}$ Symposium in Civil Engineering. Available at http://www.phd.bv.tum.de/.

Haber, Z. B., Munoz, J. F., and Graybeal, B. A. (2017). Field Testing of an Ultrahigh Performance Concrete Overlay. Available at https://rosap.ntl.bts.gov/ view/dot/37821.

Hadl, P., della, P. R., Hoang, K. H., Hoang, N. V., and Pilch, E. (2015). Anwendung von UHPC als direkt befahrener Aufbeton bei der Integralisierung eines bestehenden Brückenbauwerks in Österreich. Beton- und Stahlbetonbau 110, 162-170. doi:10.1002/best.201400091
Hajiesmaeili, A., Pittau, F., Denarié, E., and Habert, G. (2019). Life Cycle Analysis of Strengthening Existing RC Structures with R-PE-UHPFRC. Sustainability 11, 6923. doi:10.3390/su11246923

Holcim (2011). Béton fibré à ultra-hautes performances.

Holcim (2021). Europas erste komplett mit UHFB gebaute Strassenbrücke steht im Tessin. Holcim Schweiz, Ihr Partner für Zement, Kies und Beton. Available at https://www.holcim.ch/de/europas-erste-komplett-mit-uhfb-gebaute-strassenbrueckesteht-im-tessin (Accessed March 9, 2021).

Kälin, E. (2020). Erste Holz-UHFB-Verbundbrücke für Schwerlasten in der Schweiz | Espazium. Available at https://www.espazium.ch/de/aktuelles/ erste-holz-uhfb-verbundbruecke-fuer-schwerlasten-der-schweiz (Accessed March 4, 2021).

Kosaka, T., Kanaji, H., Ichinomiya, T., and Saito, K. (2015). Development of a Highway Bridge Deck Using Ultra-high Performance Fiber- Reinforced Concrete. IABSE Symp. Rep. 104, 1-8. doi:10.2749/222137815815775231

Kwon, S., Nishiwaki, T., Kikuta, T., and Mihashi, H. (2013). Experimental Study on Self-Healing Capability of Cracked Ultra-high-performance Hybrid-FiberReinforced Cementitious Composites. Cement Sci. Concrete Techn. 66 (1), 552-559. doi:10.14250/cement.66.552

López, J., Coll, A., Serna, H., and Galàn, F. (2016). The UHPFRC Pedestrian Bridge above the V-21 Highway in Puzol, Valencia: Design, Construction and Cost. in.

Martin-Sanz, H., Chatzi, E., and Brühwiler, E. (2016). "The Use of Ultra High Performance Fibre Reinforced Cement-Based Composites in Rehabilitation Projects: a Review"in Proceedings of the 9th International Conference on Fracture Mechanics of Concrete and Concrete Structures. doi:10.21012/ FC9.219

Martin-Sanz, H., Tatsis, K., Chatzi, E., Brühwiler, E., Stipanovic, I., Mandic, A., et al. (2018). Towards the Use of UHPFRC in Railway Bridges: the Rehabilitation of Buna Bridge. In (Ghent, Belgium: CRC PRESS-TAYLOR \& FRANCIS GROUP). Available at https://infoscience.epfl.ch/record/262870 (Accessed October 25, 2020).

Martín-Sanz, H., Tatsis, K., Dertimanis, V. K., Avendaño-Valencia, L. D., Brühwiler, E., and Chatzi, E. (2020). Monitoring of the UHPFRC Strengthened Chillon Viaduct under Environmental and Operational Variability. Struct. Infrastructure Eng. 16, 138-168. doi:10.1080/ 15732479.2019.1650079

Mazzacane, P., Ricciotti, R., and Teply, F. (2011). The Passerelle des Anges Footbridge. Designing and Building with UHPFRC, 111-124. doi:10.1002/ 9781118557839.ch9

MCS (2021). UHPFRC MAP for Switzerland. Available at https://www.epfl.ch/ labs/mcs/mcs-laboratory-for-maintenance-and-safety-of-structures/uhpfrc-mapswitzerland/ (Accessed September 1, 2021).

Methner, R., and Müller, R. (2019). Brückeninstandsetzung, Ertüchtigung und Abdichtung mit Ultrahochfestem-Faserbeton (UHFB). Beton- und Stahlbetonbau 114, 126-133. doi:10.1002/best.201800088

Nunes, S., Pimentel, M., Ribeiro, F., Milheiro-Oliveira, P., and Carvalho, A. (2017). Estimation of the Tensile Strength of UHPFRC Layers Based on Nondestructive Assessment of the Fibre Content and Orientation. Cement and Concrete Composites 83, 222-238. doi:10.1016/j.cemconcomp.2017.07.019

Núñez, A., Patiño, J., Arango, S., and Echeverri, W. (2019). Review of First Structural Applications of UHPC in Colombia. Int. Interactive Symp. Ultra-High Perform. Concrete 2. doi:10.21838/uhpc.9701

Oesterlee, C., Brühwiler, E., and Denarié, E. (2008a). Structural Behaviour of Composite Elements Combining Reinforced Ultra-high Performance FibreReinforced Concrete (UHPFRC) and Reinforced Concrete. Stuttgart, Germany.

Oesterlee, C., Sadouki, H., and Brühwiler, E. (2008b). Structural Analysis of a Composite Bridge Structure Combining UHPFRC and Prestressed concrete. In (Uni Kassel). Available at https://infoscience.epfl.ch/record/133586/files/Paper \%20FE\%20analysis\%20UHPFRC\%20CO\%20HS\%20EB.pdf.

Pelke, E., Jaborek, A., Berger, D., Bruehwiler, E., Orgass, M., Klitsch, B., et al. (2018). Ueberfuehrungsbauwerk der L3378 bei Fulda-Lehnerz. Erster Einsatz von UHFB in Deutschland im Strassenbrueckenbau. Teil 1: Projektentwicklung und Baudurchfuehrung, Teil 2: Betontechnologie und Qualitaetssicherung. Beton- und Stahlbetonbau 113. , 2018 Available at https://trid.trb.org/view/ 1569982 (Accessed March 24, 2021).

Robyr, D., Galrito, R., and Brühwiler, E. (2015). Passerelle du Martinet en BFUP armé,"in 2ème Journée d'étude Béton fibré ultra-performant - Concevoir, 
dimensionner, construire, Haute école d'ingénierie et d'architecture, Fribourg, Switzerland, October 22, 2015, 75-78.

Rossi, P. (2002). Development of New Cement Composite Material for Construction. Dundee, Sotland: Thomas Telford Publishing, 17-29.

Sadouki, H., Brühwiler, E., and Zwicky, D. (2015). Chillon Viaduct Deck Slab Strengthening Using Reinforced UHPFRC: Numerical Simulation of Full-Scale Tests. in.

Sadouki, H., Brühwiler, E., and Zwicky, D. 2015). Chillon Viaduct Deck Slab Strengthening Using Reinforced UHPFRC: Numerical Simulation of Full-Scale Tests, 122, 123. doi:10.1201/b18972-79

Sadouki, H., Denarié, E., and Brühwiler, E. (2017). Validation of a FEA Model of Structural Response of RC-Cantilever Beams Strengthened with a (R-) UHPFRC Layer. Construction Building Mater. 140, 100-108. doi:10.1016/ j.conbuildmat.2017.02.090

Sameer, H., Weber, V., Mostert, C., Bringezu, S., Fehling, E., and Wetzel, A. (2019). Environmental Assessment of Ultra-high-performance concrete Using Carbon, Material, and Water Footprint. Materials 12, 851. doi: $10.3390 / \mathrm{ma} 12060851$

Sawicki, B., and Brühwiler, E. (2021). Fatigue Resistance of Reinforced UHPFRC Beams. Int. J. Fatigue 148, 106216. doi:10.1016/j.ijfatigue.2021.106216

Sawicki, B., and Brühwiler, E. (2020). Long-term Strain Measurements of Traffic and Temperature Effects on an RC Bridge Deck Slab Strengthened with an R-UHPFRC Layer. J. Civil Struct. Health Monit. 10, 333-344. doi:10.1007/ s13349-020-00387-3

Shao, X., Deng, L., and Cao, J. (2019). Innovative Steel-UHPC Composite Bridge Girders for Long-Span Bridges. Front. Struct. Civ. Eng. 13, 981-989. doi:10.1007/s11709-019-0531-9

Shen, X., and Brühwiler, E. (2020). Influence of Local Fiber Distribution on Tensile Behavior of Strain Hardening UHPFRC Using NDT and DIC. Cement Concrete Res. 132, 106042. doi:10.1016/j.cemconres.2020.106042

Swiss Society of Engineers and Architects (2011). Existing Structures, SIA. Zurich, Switzerland: Swiss Society of Engineers and Architects 269, 269/ $1-269 / 7$.
Swiss Society of Engineers and Architects (2016). Technical Leaflet on UHPFRC: Materials, Design and Application. Zürich, Switzerland: SIA Zürich.

Tanaka, Y., Musya, H., Ootake, A., Shimoyama, Y., and Kaneko, O. (2002). Design and Construction of Sakata-Mirai Footbridge Using Reactive Powder concrete. Osaka, Japan: Thomas Telford Publishing, 103-104.

Toutlemonde, F., Roenelle, P., Hajar, Z., Simon, A., Lapeyrere, R., Martin, R., et al. (2013). Long-term Material Performance Checked on World's Oldest UHPFRC Road Bridges at Bourg-Lès-Valence.

Walo (2020). UHFB Bridge in Tavern. Available at https://walo.ch/projekte/uhfbbruecke-in-taverne/ (Accessed March 9, 2021).

Wassmann, K., and Brühwiler, E. (2016). Strengthening of RC Slabs Using UHPFRC - Concepts and Applications. in.

Yoo, D.-Y., and Yoon, Y.-S. (2016). A Review on Structural Behavior, Design, and Application of Ultra-high-performance Fiber-Reinforced Concrete. Int. J. Concr Struct. Mater. 10, 125-142. doi:10.1007/s40069-016-0143-x

Conflict of Interest: The authors declare that the research was conducted in the absence of any commercial or financial relationships that could be construed as a potential conflict of interest.

Publisher's Note: All claims expressed in this article are solely those of the authors and do not necessarily represent those of their affiliated organizations, or those of the publisher, the editors and the reviewers. Any product that may be evaluated in this article, or claim that may be made by its manufacturer, is not guaranteed or endorsed by the publisher.

Copyright $\odot 2021$ Bertola, Schiltz, Denarié and Brühwiler. This is an open-access article distributed under the terms of the Creative Commons Attribution License (CC $B Y$ ). The use, distribution or reproduction in other forums is permitted, provided the original author(s) and the copyright owner(s) are credited and that the original publication in this journal is cited, in accordance with accepted academic practice. No use, distribution or reproduction is permitted which does not comply with these terms. 